Review Article

\title{
Inflammatory and Anti-Inflammatory Equilibrium, Proliferative and Antiproliferative Balance: The Role of Cytokines in Multiple Myeloma
}

\author{
Caterina Musolino, ${ }^{1}$ Alessandro Allegra, ${ }^{1}$ Vanessa Innao, ${ }^{1}$ Andrea Gaetano Allegra, ${ }^{1}$ \\ Giovanni Pioggia, ${ }^{2}$ and Sebastiano Gangemi ${ }^{2,3}$ \\ ${ }^{1}$ Division of Hematology, Department Patologia Umana dell'Adulto e dell'Età Evolutiva, University of Messina, Località Gazzi, \\ Via Consolare Valeria, Messina, Italy \\ ${ }^{2}$ Institute of Applied Sciences and Intelligent Systems "Eduardo Caianiello" (ISASI)-National Research Council of Italy (CNR), \\ Messina Unit, Via Torre Bianca, Messina, Italy \\ ${ }^{3}$ School and Division of Allergy and Clinical Immunology, Department of Clinical and Experimental Medicine, University Hospital \\ "G. Martino", Località Gazzi, Via Consolare Valeria, Messina, Italy
}

Correspondence should be addressed to Alessandro Allegra; aallegra@unime.it

Received 24 May 2017; Accepted 11 September 2017; Published 26 September 2017

Academic Editor: Mirella Giovarelli

Copyright ( 92017 Caterina Musolino et al. This is an open access article distributed under the Creative Commons Attribution License, which permits unrestricted use, distribution, and reproduction in any medium, provided the original work is properly cited.

\begin{abstract}
Multiple myeloma (MM) is typically exemplified by a desynchronized cytokine system with increased levels of inflammatory cytokines. We focused on the contrast between inflammatory and anti-inflammatory systems by assessing the role of cytokines and their influence on MM. The aim of this review is to summarize the available information to date concerning this equilibrium to provide an overview of the research exploring the roles of serum cytokines in MM. However, the association between MM and inflammatory cytokines appears to be inadequate, and other functions, such as pro-proliferative or antiproliferative effects, can assume the role of cytokines in the genesis and progression of MM. It is possible that inflammation, when guided by cancer-specific Th1 cells, may inhibit tumour onset and progression. In a Th1 microenvironment, proinflammatory cytokines (e.g., IL-6 and IL-1) may contribute to tumour eradication by attracting leucocytes from the circulation and by increasing $\mathrm{CD} 4{ }^{+} \mathrm{T}$ cell activity. Hence, caution should be used when considering therapies that target factors with pro- or anti-inflammatory activity. Drugs that may reduce the tumour-suppressive Th1-driven inflammatory immune response should be avoided. A better understanding of the relationship between inflammation and myeloma will ensure more effective therapeutic interventions.
\end{abstract}

\section{Introduction}

Multiple myeloma (MM) is a clonal B cell neoplasia that results from the growth of malignant plasma cells within the bone marrow (BM), in close connection with other cells in the bone environment. Stromal cells sustain MM cell persistence and growth [1]. Amongst them, inflammatory cells have a crucial role in tumour growth and $\mathrm{MM}$ progression [2].
In fact, the relationships of myeloma cells with BM stromal cells are relevant for their increased proliferation, homing pattern, and survival [2]. The BM environment and myeloma cells stimulate paracrine or autocrine secretion of several mediators. In fact, the BM microenvironment in MM subjects displays high levels of HGF, interleukin- (IL-) 2R, IL-16, EGF, and cytokines induced by interferon- $\gamma$ (IFN- $\gamma$ ) [3]. Many of these cytokines are considered to be promoters of MM development [4-9], sometimes operating 
as growth factors for MM cells and sometimes promoting cellular adhesion. Other cytokines appear to increase angiogenesis or osteoclastogenesis [10-16].

It is well known that cytokines are implicated both in inflammatory and anti-inflammatory processes and are the manifestation of a system that includes genes and polymorphisms. Many of these factors that are altered in the serum or bone marrow of MM subjects have proinflammatory activity, such as IL-1, IL-6, IL-12, IL-15, IL-16, IL-17, IL-18, IL-22, IL-23, TNF- $\alpha$, and IFN- $\gamma$, while others exert antiinflammatory effects, such as IL-1R $\alpha$, IL-4, IL-10, IL-11, TGF- $\beta 1$, heat-shock proteins (HSPs), and lipoxin A4.

Although essential for defence against microbial infection, the inflammatory response requires stringent control because incorrect inflammatory signals and disproportionate cell death are the cause of several diseases.

Tumour growth is also associated with significant inflammation; an increase in proinflammatory cytokine levels can support the progression of neoplasia [17]. Cytokines secreted by plasma cells and T lymphocyte subsets can create an environment in the BM that fosters malignant cell development.

\section{T Lymphocyte Subsets in Multiple Myeloma}

The imbalance of $\mathrm{T}$ lymphocyte subsets may perform relevant roles in $\mathrm{MM}[18,19]$.

Depending on the substances delivered and functions, CD4+ T cells can be grouped into several subsets comprising T helper 1 (Th1), Th2, Th17, and CD4+ CD25+ T regulatory (Treg) cells $[20,21]$. Th1 cells produce interferon gamma (IFN- $\gamma)$ and stimulate the cell-mediated immune response, while Th2 cells deliver IL-4 and inhibit the Th1 cellmediated response. Th17 cells generate IL-17A, IL-6, and TNF- $\alpha$ implicated in stimulating inflammation [22, 23]. Treg cells repress effector T cell growth by producing TGF- $\beta$ and IL-10, which exert immunomodulatory actions. The imbalance between Treg and Th17 cells has become a key function in inflammatory diseases.

Recently, Th17 cells have been implicated in the occurrence of MM and its complications [24-28].

The CD4+ Th1 and CD4+ Th17 subsets in subjects with MM were considerably higher than those in healthy subjects, as were the levels of T-bet and RORgamma mRNA [29].

Wang et al. noted that the numbers of another T cell type, Th22 cells, were significantly higher in peripheral blood (PB) and bone marrow (BM) of MM subjects and recovered in subjects with complete remission after treatment. Furthermore, the numbers of Th22 and Th17 cells were greater in stage III than in stages I and II MM [30].

Treg cells have a relevant function in the protection of self-tolerance and of immune responses against tumour cells. The anomalous Treg activity in MM subjects could, on the other hand, participate in the MM-related immune dysfunction [31].

The action of Tregs in the biology of MM has been studied by several authors. Nevertheless, many in vitro or in vivo data remain ambiguous. For instance, one study calculated the number of Tregs in the peripheral blood (PB) of controls versus subjects with MGUS and MM and displayed a significant decrease in the number of Treg cells. These cells were reported as dysfunctional and incapable of suppressing the growth of T lymphocytes. However, another study evaluated the number and function of Tregs in the PB and BM of controls and MM subjects and did not show a modification in the proportion of Treg cells between the two sites, between either group of subjects [32].

Huang et al. investigated the action of Tregs in the onset of MM-related kidney impairment (KI). The Tregs significantly decreased in the MM-related KI subjects compared with the controls. The number of Tregs was negatively correlated with blood urea nitrogen, serum IL-6, IL-4, $\beta 2$-microglobulin, monoclonal immunoglobulin, BM plasma cell percentages, and proteinuria, but they were positively correlated with the glomerular filtration rate. Tregs gradually diminished as the stage of disease increased [33].

\section{Inflammatory and Anti-Inflammatory Balance in MM}

In this review, we have concentrated our attention on the equilibrium between the inflammatory and antiinflammatory systems by assessing the action of cytokines and their impact on MM. The aim of our work is to summarize what is known to date about this balance, providing an overview of the research examining the role of serum cytokines in MM (Figures 1 and 2).

However, as we shall demonstrate later, the MMinflammatory cytokine increase appears to be inadequate, and other functions such as pro-proliferative or antiproliferative effects can assume the activities of cytokines in the genesis and progression of MM.

\section{Proinflammatory Cytokines}

4.1. IL-1. IL-1 is a powerful proinflammatory cytokine that operates as an endogenous pyrogen. It is delivered by fibroblasts, monocytes, tissue macrophages, and dendritic cells (DCs), but it is also produced by B lymphocytes, epithelial cells, and natural killer (NK) cells.

IL-1 was first cloned in the 1980s and quickly found to be a key agent in the control of inflammatory processes. The name IL- 1 encompasses two cytokines, IL- $1 \alpha$ and IL- $1 \beta$, which are produced by two diverse genes. The actions of IL-1 are tightly regulated by numerous inhibitors, such as IL-1 receptor antagonist (IL-1Ra), IL-1 receptor type II (IL-1RII), and additional soluble receptors [34].

The cytokine has various potentiating effects on cell growth, differentiation, and the function of several immunocompetent cells. It plays a role in numerous inflammatory diseases by initiating immune and inflammatory responses [35].

Numerous researchers have evaluated the role of IL-1 in the pathogenesis of MM. Like mature B lymphocytes, the myeloma plasma cell generates IL-1. In the BM environment, stromal cells react to low levels IL-1 and produce large quantities of IL-6, which in turn stimulate the survival of the myeloma cells [36]. Blockade of IL-1 results in a decrease in IL-6 activity [37]. 


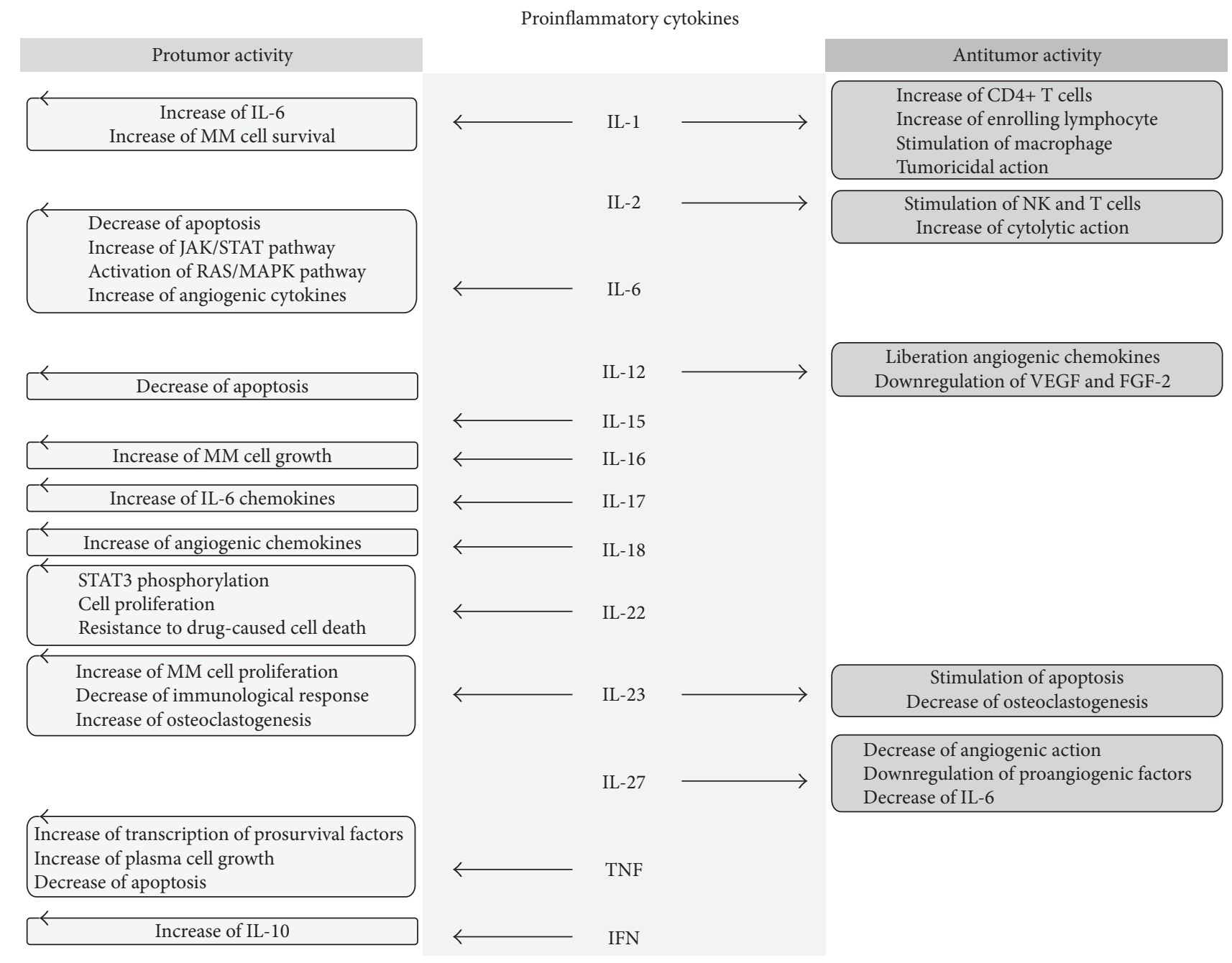

FIGURE 1: Effects of proinflammatory cytokines action on multiple myeloma cells and, therefore, on the tumour itself. Some of them have only protumour action, while for others there is a simultaneous dual mechanism of action pro and antitumour.

An in vivo work confirmed that IL- $1 \beta$ has a relevant role in the conversion of latent myeloma to active MM. The aim of this study was to decelerate or prevent progression of the disease. Subjects with latent/indolent MM at high risk of progression were treated with anakinra, an inhibitor of IL-1, for 6 months. During the treatment, there was a reduction in Creactive protein (CRP) and a decrease in the plasma celllabelling index. After 6 months of treatment, a low dose of dexamethasone was added. Of the 47 subjects who received anakinra, progression-free disease (PFD) was achieved after 3 years and 4 years in 8 subjects. Subjects with a reduction in serum CRP of $15 \%$ after 6 months of therapy achieved PFD after 3 years compared with 6 months in subjects with less than a $15 \%$ reduction [38].

A different inhibitor of IL-1 is the engineered P2D7KK antibody. This substance has a strong affinity for IL- $1 \beta$, resulting in robust neutralization of human IL-1 $\beta$. In an experimental model, P2D7KK therapy reduced MMinduced lethality; 70\% of P2D7KK-treated animals survived compared with $20 \%$ in the control group. Remarkably, the survival percentage inversely correlated with the serum concentrations of IL- 6 , further supporting the relevant role of IL- $1 \beta$ in the pathway leading to MM [39].

4.2. IL-2. IL-2 is principally generated by $\mathrm{CD} 8^{+}$and $\mathrm{CD} 4^{+} \mathrm{T}$ cells. Target cells of IL-2 comprise CD4 CD8 T cells, B cells, and NK cells. IL-2 has a relevant role in T cell-dependent responses.

IL-2 was one of the first cytokines to be accepted for the treatment of tumours, despite its having one of the most complicated and, in some circumstances, incongruous roles in immune stimulation. Not only does IL-2 strongly stimulate $\mathrm{NK}$ and $\mathrm{T}$ cell growth and augment their cytolytic action, but it also sensitizes $\mathrm{T}$ cells to activation-induced cell death and is required for Treg cells to reduce persistent immune responses [40].

Benson et al. have established that NK cells derived from MM subjects exhibit the inhibitory receptor PD-1, whereas NK cells from healthy subjects do not show this receptor unless activated by IL-2 [41].

Emerging evidence indicates that NK cells also have antiMM activity [42], and in vitro studies have revealed that 
Anti-inflammatory cytokines

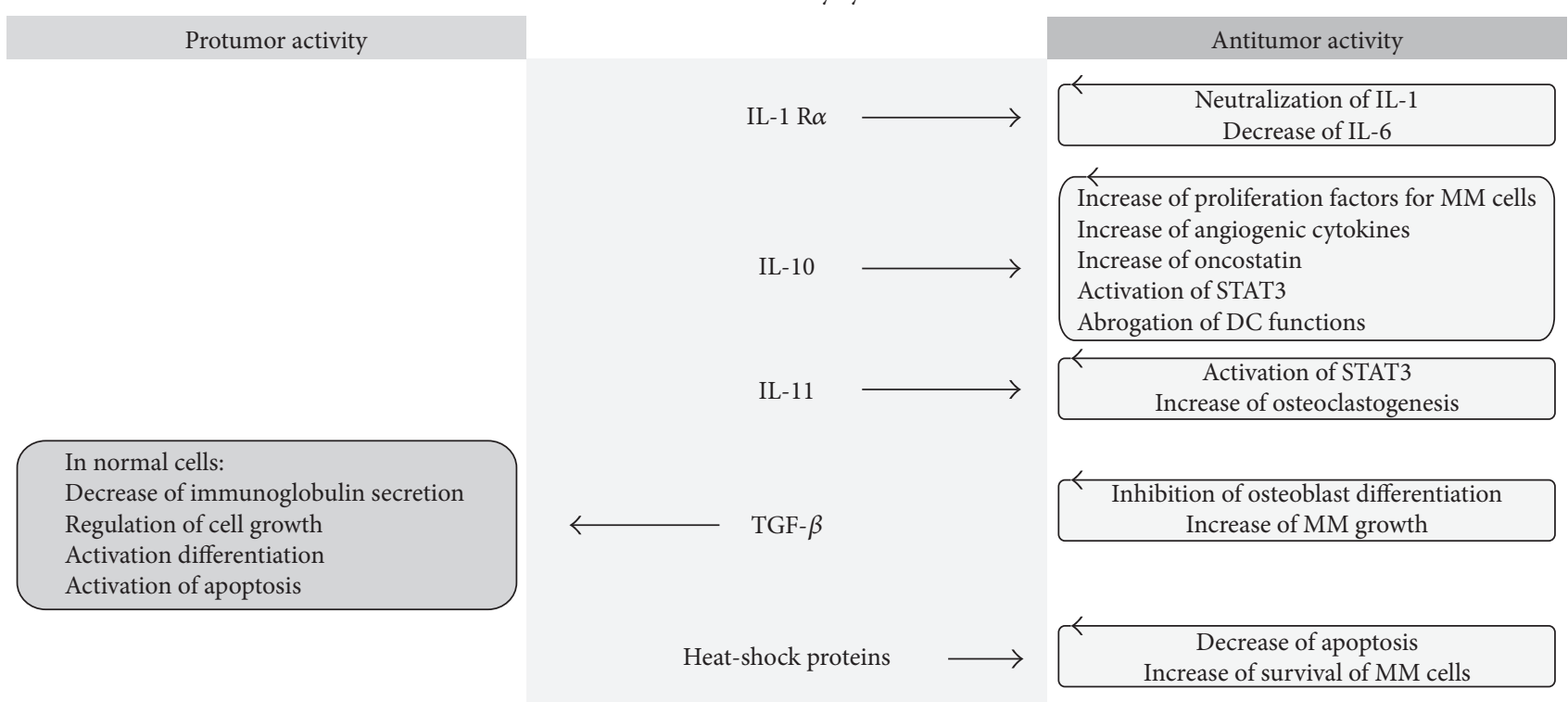

FIGURE 2: All anti-inflammatory cytokines have an antitumour effect, except for TGF- $\beta$.

allogeneic and auto NK cells have the capability to kill CD138-purified MM cells [43].

In human subjects, NK cells are controlled by killer immunoglobulin-like receptors (KIRs) that identify allotypic determinants exhibited by diverse human leucocyte antigen (HLA) class I alleles.

A study has revealed that administration of IL-2activated haploidentical killer immunoglobulin-like receptor (KIR) ligand-mismatched NK cells to MM subjects was effective, and $50 \%$ of the subjects achieved nearly complete remission [44].

Moreover, it is well known that hypoxia decreases NK cell eradication of MM cell lines in an oxygen-dependent mode. During hypoxia, NK cells had a conserved capability to degranulate in response to target cells, although the rate of degranulating NK cells was slightly diminished. Preactivation of NK cells by IL-2 abolished the detrimental actions of hypoxia and augmented NKG2D expression, highlighting that NK cell-activated IL-2 can have anti-MM actions, even under hypoxic conditions [45].

4.3. IL-6. IL-6 is a pleiotropic cytokine implicated in the control of acute responses, immune reactions, haematopoiesis, and inflammation. It has context-dependent pro- and anti-inflammatory activities with diverse signalling pathways. IL-6 is generated by monocytes, endothelial cells, macrophages, and fibroblasts in response to diverse stimuli (TNF- $\alpha$, IL-1, and IL-17) during systemic inflammation [46]. It stimulates the growth and activation of $\mathrm{T}$ cells, the differentiation of $\mathrm{B}$ cells, and the control of the acute-phase response [47].

IL-6 expression is generally low, and serum concentrations are normally nondetectable in the absence of inflammation.

It is implicated in lymphoid tumours and functions as a crucial growth factor for MM by decreasing apoptosis caused by growth factor withdrawal and by establishing the expression of the cell death receptor Das [48].

IL- 6 binds to IL- 6 receptor (IL-6R) to initiate IL-6 signalling. IL-6R, which is generated by MM cells, consists of an alpha (gp80) and a signal transducer beta (gp130) chain. This structure binds to the signal transducer membrane protein gp130, which stimulates Janus kinases/signal transduceractivator of transcription (JAKs/STAT) and the GTPase/ mitogen-activated protein kinase (RAS/MAPKs) pathway. It is well known that JAK/STAT has a role in MM growth and inhibition of apoptosis, while RAS/MAPK is active in proliferation.

There is also a soluble form of gp80 (sIL-6R) that is produced either by proteolytic cleavage or by transcription of a splice variant. sIL-6R is increased in MM, with serum concentrations that are interrelated to both disease and angiogenic activity factors [49]. In fact, it has been established that the mean levels of sIL-6R, and the value of Ki-67, were considerably higher in MM compared with health subjects. Moreover, there is a positive correlation between plasma cell proliferation and diverse angiogenic cytokines, such as IL-18 and HGF, with sIL-6R [50].

Nevertheless, IL-6 not only participates in the proliferation of myeloma cells, but also is a main morbidity factor in MM subjects. Augmented IL- 6 concentrations are associated with disease-related renal involvement, thrombocytosis, anaemia, bone reabsorption, and a prothrombotic state. In numerous malignancies, encompassing MM, lymphoma, and lung cancer, high serum concentrations of IL-6 have been associated with a poor prognosis $[51,52]$.

The cellular source of IL- 6 in MM patients has long been unclear. IL- 6 was first identified as an autocrine factor generated by malignant plasma cells. More recent research has shown that IL-6 is a paracrine factor delivered by the microenvironment, principally by cells from the myeloid compartment. Matthes et al. have validated that IL-6 derives from 
myeloid precursors. They have also confirmed that IL-6 augments the pool of myeloid cells to generate a second factor for MM cells, a proliferation-inducing ligand (APRIL). These data establish a novel motivation for IL-6 inhibition in MM subjects [53].

Because IL-6 is known as a proliferative factor in MM cells, inhibition of IL-6 signalling was established in 1991 as a therapeutic method for MM subjects. Unfortunately, the first clinical trial did not demonstrate a clear advantage; however, despite this failure, the chances of IL-6 antagonism remain still high. Siltuximab is a chimeric anti-IL-6 antibody, and it was studied for its advantageous anti-IL-6 effects on tumours, such as MM $[54,55]$. Nevertheless, therapy with siltuximab intensified the possibility of upper respiratory tract infections or other adverse effects including fatigue, nausea, rash, pruritus, dyspnoea, increased weight gain, thrombocytopenia, and neutropenia [56].

Another method to reduce IL-6 production could consist of the administration of clarithromycin (CAM) (or 6-Omethyl erythromycin), a macrolide antibiotic [57].

There is evidence that CAM is a powerful inhibitor of autophagy in MM [58]. The proteasome inhibitor bortezomib (Bor) also causes autophagy. The combination of Bor and CAM caused augmented cytotoxicity compared with Bor alone [59]. Durie et al. registered a greater than 50\% response rate [60]. Other authors utilizing CAM as monotherapy could not validate its activity in MM [61-64].

Since CAM reduces IL-6 secretion, it might have a direct anticancer action in $\mathrm{MM}[65,66]$.

4.4. IL-12. IL-12 is a cytokine that is able to stimulate both innate and adaptive immunity. It causes Th1-cell cytotoxicity and has been shown to have strong immunomodulatory and antitumour activities [35].

The inflammatory activity of IL-12 has been confirmed in subjects with psoriatic arthritis (PsA). Ustekinumab is a monoclonal antibody that binds to the p40-subunit of IL12 , and ustekinumab therapy resulted in considerably improved PsA activity [67].

Nevertheless, although IL-12 is an inflammatory cytokine, in this case the prevalent activity of the cytokine seems to be protection against neoplastic disease.

IL-12 exerts its antitumour activity via immunostimulatory and antiangiogenic actions related to the production of IFN- $\gamma$, which stimulates the liberation of the antiangiogenic chemokines CXCL9, CXCL10, and CXCL11. Moreover, IL-12 downregulates the liberation of vascular endothelial growth factor (VEGF) and fibroblast growth factor-2 (FGF-2) [68-75].

The IL-12RB2 gene encoding the IL-12R chain acts as a tumour suppressor in neoplastic B cells from several chronic lymphoproliferative diseases and acute lymphoblastic leukaemia. Airoldi et al. have also showed that $I L-12 r b 2-$ deficient mice develop multiorgan lymphoid infiltrates, $\mathrm{CD} 138^{+}$cell hyperplasia, and display IL-6 upregulation. Moreover, $I L-12$ rb2 knockout animals have localized lymph node plasmacytoma, which is probably related to IL-6 overexpression [76-79].
In another study, Airoldi et al. examined the function of IL-12R $\beta 2$ in MM pathogenesis. They demonstrated that IL$12 \mathrm{R} \beta 2$ was present in primary MM cells but was downregulated in comparison to polyclonal plasmablastic cells and plasma cells. IL- 6 reduced IL-12R $\beta 2$ expression on plasmablastic and MM cells. Furthermore, IL-12 decreased the proangiogenic action of primary MM cells in vitro and reduced the tumourigenicity of the NCI-H929 cell line in mice by reducing cell growth and angiogenesis. This phenomenon depended on reduced expression of several proangiogenic genes and upregulated expression of several antiangiogenic genes, such as platelet factor-4, IFN- $\gamma$, IFN$\alpha$, and TIMP-2. Reduction of the angiogenic action of MM cells was correlated to downregulated expression of the proangiogenic genes CD13, AKT, CCL11, and vascular endothelial-cadherin, and the upregulation of an IFN- $\gamma$-correlated antiangiogenic pathway. Therefore, IL-12R $\beta 2$ limits MM cell proliferation, and targeting of IL-12 to MM cells could be a novel therapeutic approach [80].

Wang et al. examined the possibility of using proteasome inhibition by Bor and immune treatment with IL-12 to augment the antitumour efficacy relative to the actions of either of those agents alone. IL-12 therapy alone caused a mild reduction in tumour volume compared with the control. Bor alone inhibited tumour proliferation, resulting in a decrease in tumour volume by $\sim 65 \%$ after 15 days of treatment. The combination treatment produced $\sim 75 \%$ decreases in tumour growth, considerably exceeding the decrease caused by Bor monotherapy. Tumour growth resumed following the conclusion of Bor therapy at 2 weeks, although the tumour size was still smaller than that in the NS and IL-12 animals. This rebound of tumour enlargement was entirely avoided with the combination treatment, and the tumour volume continued to decline over the time course. Moreover, combination treatment reestablished the Borinduced functional deficiency of the NK cells relative to Bor administration alone [81].

To establish the effectiveness and toxicity of IL-12, the Eastern Oncology Cooperative Group (ECOG) conducted a phase II trial of this substance in treated subjects with plateau phase MM. Half the subjects received IL-12 in combination with vaccines against Streptococcus pneumoniae and Haemophilus influenza, and half received IL-12 at 30 days after receiving their vaccines. Of 48 subjects, there were $4 \mathrm{CR}$ $(8.3 \%)$. The progression-free survival and median survival were 11.4 and 42.8 months, respectively. Grade 3 or 4 nonhaematologic toxicity (63\% with intravenous IL-12 and $31 \%$ with subcutaneous IL-12) was detected [82].

Finally, IL-12 alone or with GM-CSF has been utilized to increase anti-idiotype vaccines in subjects with MM [83].

4.5. $I L-15$. IL-15 is a cytokine that is able to maintain the cellular immune response, stimulating the growth of human memory T cells. IL-15 is comparable to IL- 2 in terms of biological actions [84].

IL-15 binds to IL-15 receptor $\alpha$ (IL-15R $\alpha$ ) and is presented in trans to the IL-2/IL-15 receptor $\beta$ common $\gamma$ chain (IL-15R $\beta \gamma_{\mathrm{c}}$ ) complex. IL-15 and IL-2 exhibit the same binding to IL-15R $\beta \gamma_{c}$ and act via the STAT3 and 
STAT5 pathways. Nevertheless, unlike IL-2, IL-15 does not sustain the maintenance of Treg cells or induce cell death of activated $\mathrm{CD}^{+} \mathrm{T}$ cells. Moreover, IL-15 is the only cytokine recognized to cause antiapoptotic signalling to effector $\mathrm{CD}^{+} \mathrm{T}$ cells $[85,86]$.

IL-15 is a cytokine with proinflammatory activity that seems to provide a protective activity against solid cancers, although its effect could be diverse in the case of MM.

In fact, although IL-15 displays antitumour activities against solid cancers in experimental animal models and has been recognized as one of the most encouraging immunotherapeutic drugs [87-89], only a small number of studies have demonstrated the effectiveness of IL-15 against haematologic tumours.

In a study conducted in MM patients, IL-15 was elevated in the patients compared with the controls. Serum IL-15 levels were increased in MM stage III subjects in comparison with stages I and II, although this difference did not achieve statistical significance. There was a positive correlation between the serum IL-15 and IL-10 concentrations [90].

Investigation of expression models of the IL-15R subunits in six MM cell lines and in the neoplastic cell fraction of $14 \mathrm{MM}$ subjects by Tinhofer et al. showed that malignant plasma cells presented all three elements of the IL-15R heterotrimer [48]. However, whereas healthy B cells from normal subjects downregulate IL-15R $\alpha$ after IL-15 administration, MM cells do not show such a decrease in response to IL-15 stimulation. In a different study, IL-15 overexpression in MM plasma cells protected them against apoptosis [48]. These results indicate that MM cells can reduce apoptosis and support themselves via autocrine IL-15 stimulation, thus becoming less dependent upon their microenvironment.

In any case, data from other studies have complicated interpretation of the results.

ALT-803, a fusion protein made by an IL-15 superagonist mutant and a dimeric IL-15 receptor, was discovered to display significantly stronger in vivo activity than IL-15 towards $\mathrm{T}$ and NK cells. In another study, Xu et al. found that a dose of ALT-803, but not IL-15 alone, eradicated 5T33P and MOPC-315P MM cells in the BM of tumour-bearing mice. ALT-803 therapy significantly augmented the survival of MM-bearing mice and provoked resistance to rechallenge with the same cells via a $\mathrm{CD} 8^{+} \mathrm{T}$ cell-dependent mechanism. ALT-803 therapy stimulated $\mathrm{CD}^{+} \mathrm{T}$ cell production of large quantities of IFN- $\gamma$ and augmented the proliferation of $\mathrm{CD} 8^{+} \mathrm{CD} 44^{\text {high }}$ memory $\mathrm{T}$ cells in vivo.

ALT-803-activated $\mathrm{CD}^{+}$memory $\mathrm{T}$ cells also displayed nonspecific cytotoxicity against MM cells in vitro, whereas IFN- $\gamma$ had no direct effects on MM cell growth. The antiMM activity of ALT-803 was lost in tumour-bearing IFN- $\gamma$ knockout mice [91].

4.6. IL-16. IL-16 is recognized to cause chemotaxis of CD4 T cells, eosinophils, and monocytes [92].

Numerous works were able to demonstrate the elevated levels of IL-16 in the BM of MM patients [93, 94]. Nevertheless, the cell types responsible for IL-16 secretion remain undetermined. Alexandrakis et al. indicated that IL-16 is produced by MM cell lines and that augmented IL-16 concentrations were present in the BM of MM patients and post-alloSCT subjects. Furthermore, they also confirmed the presence of a distinct concentration gradient of IL-16 from the $\mathrm{PB}$ to the $\mathrm{BM}$. Moreover, IL-16 concentrations were significantly correlated with the grade of BM infiltration by MM cells. Consequently, IL-16 might have a significant role in the pathogenesis of MM [95].

Serum IL-16 was also evaluated before and after the treatment of MM subjects. The concentrations of serum IL-16 in the MM group were much higher than those in the controls. The concentrations of serum IL-16 in the MM subjects who received treatment were all lower than those in MM subjects before therapy, and a correlation as found between concentrations of IL-16 and $\beta 2-\mathrm{MG}$ [96].

MM cell lines constitutively presented IL-16 and its receptors CD4 and/or CD9 and produced soluble IL-16. Silencing of IL-16 decreased the proliferative ability of MM cells by approximately $80 \%$ compared with untreated cells, and the use of a recombinant carboxyl-terminal IL-16 peptide reversed this activity. A monoclonal antibody directed towards IL-16 or its receptor displayed potent proliferationinhibiting effects on the tumour cells [97].

4.7. IL-17. Activated Th17 cells secrete most of the IL-17, although NK cells, $\mathrm{CD}^{+} \mathrm{T}$ cells, and neutrophils also generate variable quantities of IL-17. IL-17 stimulates the expression of several chemokines and cytokines, including IL-6, TGF- $\beta$, matrix metalloproteinase, G-CSF or GM-CSF, and intercellular adhesion molecule-1 in numerous cell types, such as bone marrow stromal cells. It also acts as an inflammation mediator. In fact, this cytokine has a relevant role in the pathogenesis of autoimmune diseases and allergies [98].

Concentrations of IL-17 in MM subjects are higher than those in controls. The levels of IL-17 in ISS I and ISS II stage subjects are not significantly different; the concentration of IL-17 in treated, retreated/refractory subjects are significantly higher than those in subjects with effective treatment, while the concentration in MM subjects is positively correlated with the level of $\beta 2$-MG. Therefore, the IL-17 level may be utilized to determine the ISS stage and therapeutic effectiveness of MM [99].

Finally, miRNAs have been implicated in the pathogenesis of MM [100]. Li et al. evaluated the role of miR-15a/16 in the pathogenesis of MM. They discovered that miR-15a/16 was downregulated in BM-derived mononuclear cells of newly diagnosed MM subjects. Moreover, they demonstrated that miR-15a/16 could reduce IL-17 concentrations in the supernatant of myeloma cells [101].

4.8. IL-18. IL-18, an $18 \mathrm{kDa}$ cytokine belonging to the IL-1 family of cytokines, contributes to angiogenesis, immune modulation, and bone metabolism. IL-18 is a powerful proinflammatory cytokine that is capable of stimulating killing by lymphocytes and is crucial to defence against critical infections [102].

IL-18 can provoke both Th1 and Th2 reactions depending on the general cytokine milieu. In fact, with IL-12, IL- 
18 provokes IFN production, whereas without IL-12, IL-18 causes IL-13 and IL-4 secretion [103].

IL-18 is believed to have angiogenic properties because it can cause endothelial cell migration in vitro and blood cell formation.

IL-18 was elevated in MM subjects than in controls [104]. Furthermore, augmented serum IL-18 in MM subjects has been shown to be associated with worse survival, advanced disease, and augmented concentrations of angiogenic cytokines $[105,106]$. Significant relationships between IL-18 with VEGF, angiogenin, and bone marrow infiltration have been demonstrated in MM subjects [107].

4.9. IL-22. IL-22 is a member of the IL-10 cytokine superfamily, which comprises powerful mediators of inflammatory responses. IL-22 is generally secreted by activated Th1type T cells, endothelial cells, NK cells, activated dendritic cells, and histiocytes [108, 109]. The transduction of IL-22 signalling is realized by binding to a heterodimeric receptor complex (IL-22R) consisting of IL-22R1 and 2, with successive activation of intracellular kinases (MAP, JAK1, and Tyk2 kinases) and transcription factors, particularly STAT3 [110, 111]. IL-22 has been shown to control the acute-phase response and to stimulate the innate immune system, cell differentiation, cell migration, and gene expression [112-114]. IL-22 may also be secreted, together with IL-17, from splenic tissue inducer-like cells and $\mathrm{T}_{\mathrm{H}} 17$ cells, in the presence of several proinflammatory cytokines such as IL-1beta, IL-6, IL-21, and IL-23 [115, 116].

Recently, a novel subset of CD4 T cells has been recognized which produces IL-22 independently of IL17 [117, 118].

Regarding the role of IL-22 in tumour immunity, IL-22producing CD4 $\mathrm{T}$ cells were discovered in malignant pleural effusion, gastric cancer, pancreatic cancer, colorectal cancer, and B-chronic lymphocytic leukaemia. In gastric cancer, IL22 levels correlated worse prognosis [119-123].

Di Lullo et al. discovered that the incidence of IL-22 T cells was significantly augmented in PB and BM of stage III and relapsed MM subjects, compared with donors or subjects with asymptomatic or stage I/II MM. Th22 cells derived from the BM of MM subjects produced IL-22 and IL-13 but not IL17. Moreover, a fraction of the MM cell lines and tumours expressed IL-22RA1 and IL-22-induced STAT3 phosphorylation, cell proliferation, and resistance to drug-induced cell death in MM cells. These data indicate that the augmented frequency of IL-22 T cells is related to a poor prognosis in MM through IL-22 protumour activity, and they suggest that interference with IL-22 signalling pathways could be useful for the treatment of MM [124].

IL-22 was higher in active MM subjects compared with both healthy controls and subjects in remission, as well as in patients who were in remission compared with controls. Moreover, IL-22 levels increased with the disease stage and correlated with IL1- $\beta$, B22M, and the degree of infiltration. Tsirakis et al. proposed that the augmented concentrations of IL-22 in active MM subjects, in parallel with the disease stage and positively correlating with IL-1beta, might characterize the inflammatory component of the disease. This augmented presence of IL-22 may increase MM growth and, moreover, contribute to the mechanisms responsible for immune deregulation [125].

4.10. IL-23. IL-23 is a proinflammatory cytokine that consists of two subunits, p19 and p40. The p40 component is shared with IL-12. However, IL-23 and IL-12 have diverse receptors and actions. While IL-12 stimulates the development of Th1 cells, which secrete IFN, IL-23 is implicated in the differentiation of Th17 cells under proinflammatory conditions, particularly in the presence of transforming growth factor- $\beta$ (TGF- $\beta$ ) and IL-6 [126].

The IL-23 receptor consists of the IL-12 receptor b1 chain and the unique IL-23 receptor chain, which is associated with STAT3 and Jak2 [127]. In leukaemic cells and T lymphocytes, IL-23 stimulates activation of STAT family members [127].

IL-23 is generated essentially by myeloid dendritic cells stimulated by Toll-like receptor 2, 4, and 8 ligands and by type 1 macrophages [128, 129]. In fact, IL-23 is considered the principal switch in numerous $\mathrm{T}$ cell-mediated inflammatory diseases, while its antitumour effects remain debatable. This proinflammatory cytokine has been shown to impair immune surveillance and augment de novo carcinogenesis and tumour neovascularization [130-132]. However, other researchers have demonstrated that IL-23 exerts antitumour activity by stimulating T and NK cells [133-137].

Regarding MM, although the entire IL-23 receptor is presented on MM cells, it remains unknown whether IL-23 is effective in terms of the modulation of MM cell growth and angiogenesis, stimulation of apoptosis and chemotaxis.

Nevertheless, IL-23 was found to be augmented in MM patients compared with healthy controls [138]. Moreover, IL-23 was associated with decreased CD8 T cell infiltration in the BM microenvironment. These data suggest a possible role of IL-23 in Th17-mediated stimulation of MM cell proliferation and inhibition of immune function [32].

Further complication the situation could be the activity of IL-23 in the genesis of bone diseases in subjects with MM.

Quinn et al. showed that IL-23 decreased osteoclastogenesis indirectly via CD4 T cells and that IL-23p19 decreased bone mass [139]. Kamiya et al. [140] demonstrated that IL23 was ineffective on RANKL expression and that osteoclastogenesis caused by soluble RANKL was, in part, suppressed by IL-23, whereas the growth of osteoclast progenitors was not altered [140].

These data suggest that under physiologic situations, IL23 favours high bone mass by reducing bone resorption, while under pathologic conditions, IL-23 has a stimulatory effect on osteoclast formation, mainly via the induction of RANKL by $\mathrm{T}$ cells and IL-17 production. In fact, the actions of Th17 and IL-17 in osteoclast activation in MM is well known [141]. As IL-23 is a cytokine implicated in Th17 differentiation and growth, it is reasonable that the high BM concentrations of IL-23 observed in MM subjects promote osteoclastogenesis via the expansion of Th17.

4.11. IL-27. IL-27 is a cytokine that belongs to the IL-12 superfamily, which comprises IL-12, IL-23, and IL-35. These 
cytokines are principally generated by antigen-presenting cells and are implicated in the control of immune responses against infections and cancer development [142].

IL-27 consists of the EBI3 and p35 components and stimulates both STAT1 and STAT3 through different IL27 receptors, the receptor subunit WSX-1 paired with the gp130 chain [143]. In $T$ lymphocytes, IL-27 stimulates STAT1 and STAT3, thus causing an increase in CD4 T cell growth, stimulation of early Th1 cell differentiation, and suppression of the differentiation of Th17 and of Th2 cells. Moreover, IL-27 plays a role in producing IL-10-regulatory T cells [144].

Plasma cells constitutively present WSX-1 and gp130, and IL-27 stimulates STAT1 phosphorylation while not influencing STAT3 or STAT5 activation [145]. Modifications of STAT activation by IL-27 may reflect the diverse capability of B cell subsets to react to IL-27. For example, IL-27 stimulates the expression of CD86, CD95, and CD54 in activated memory B cells and exhibits chemotactic activity towards plasma cells $[145,146]$.

Other researchers have confirmed that IL-27 exhibits anticancer activity towards different tumours through several mechanisms, such as through the stimulation of NK cells and the CTL response, as well as the suppression of angiogenesis. This is principally due to the generation of CXCL10 and CXCL9 [71, 76, 147].

Recent data have confirmed the antitumour effects of IL-27 on diverse haematologic malignancies in MM.

Although IL-27 does not modify MM cell growth and apoptosis, a potent decrease in the angiogenic activity of MM cells has undoubtedly been documented. It is well known that MM neoangiogenesis may be stimulated by angiogenic cytokines secreted by tumour and microenvironmental cells [148-150].

IL-27 downregulates a broad panel of proangiogenic factors in vitro, comprising VEGF angiopoietins, and matrix metalloproteinases, while upregulating the antiangiogenic factors CXCL9 and CXCL10. Hence, preclinical studies utilizing immunodeficient mice injected with MM cells have shown that IL-27 reduces MM cell growth via suppression of angiogenesis, which causes ischaemic necrosis in tumours. In this model, the principal proangiogenic factors and MM growth factors that were reduced by IL-27 were VEGF-D, IL-6, and CCL2, which also functioned as autocrine and/or paracrine growth factors $[12,151]$.

4.12. TNF. TNF was initially described as a factor that can provoke tumour cell necrosis, but it was later recognized as a proinflammatory cytokine. An incongruous TNF signalling is involved in the pathogenesis of several inflammatory diseases.

TNF binds to two diverse receptors, which are differentially present on cells and tissues and cause both dissimilar and overlapping signal transduction pathways. These different pathways lead to several responses, such as cell death, survival, growth, and differentiation [152].

Nevertheless, not only do the mechanisms decrease the propensity to undergo cancer transformation but also, the mechanisms that increase a tendency towards tumour transformation are intensified by TNF- $\alpha$ [153]. Whereas some studies have demonstrated that high concentrations of TNF- $\alpha$ reduce tumour angiogenesis in neoplastic tissues, other studies have demonstrated that TNF- $\alpha$ may operate as an endogenous tumour growth factor [153].

Binding of TNF to its receptor, TNFR1, results in the temporary formation of a primary membrane-bound signalling complex identified as complex 1, which induces the expression of prosurvival genes. Defective complex I activation causes the induction of cell death (apoptosis or necroptosis), which occurs through the internalization of complex I components and activation of secondary cytoplasmic death complexes known as complex II and necrosome.

Most studies have demonstrated a powerful association between TNF- $\alpha$ and haematologic and nonhaematologic malignancy [154].

In fact, at a molecular level, TNF engages NEMO(nuclear factor- $\kappa \mathrm{B}(\mathrm{NF} \kappa \mathrm{B})$ essential modulator-) IKK2 (I $\kappa \mathrm{B}$ kinase subunit 2, also known as IKK $\beta$ ) kinase complex, which stimulates the phosphorylation and degradation of inhibitory $\mathrm{I} \kappa \mathrm{B} \alpha$ (inhibitor of $\mathrm{NF}-\kappa \mathrm{B} \alpha$ ), releasing the RelA:p50 dimer into the nucleus though the canonical NF $\kappa$ B pathway [155]. In a negative feedback loop, RelA:p50 transcriptionally stimulates the synthesis of $\mathrm{I} \kappa \mathrm{B} \alpha$, which guarantees the postinduction decrease in the activity of RelA:p50/ $\mathrm{NF} \kappa \mathrm{B}$. TNF promotes the transcription of prosurvival factors from their cognate $\kappa \mathrm{B}$-driven promoters. It is usually assumed that RelA:p50 mediates this prosurvival $\mathrm{NF} \kappa \mathrm{B}$ action in MM cells. Notably, IKK inhibitors have been shown to sensitize MM cells to apoptotic death $[156,157]$.

Furthermore, Roy et al. reported that MM-associated noncanonical aberrations strengthen prosurvival TNF signalling to cause a prolonged TRAIL-refractory condition. These mutations did not function via a typical p52 NF $\kappa \mathrm{B}$ complex but degraded p100 to reposition RelB under $\mathrm{I} \kappa \mathrm{B} \alpha$ control, the degradation of which induced an early RelB:p50-containing NF $\kappa$ B activity [158].

In MM, TNF- $\alpha$ is implicated in the production of malignant plasma cells because the plasma cells proliferated when mononuclear cells from MM subjects were exposed to TNF- $\alpha$ in vitro [159].

Gene polymorphisms of TNF could also be important for its activity. A study conducted in $94 \mathrm{MM}$ subjects and 141 controls revealed that the A allele of TNF- $\alpha$ (-308) was expressed at lower levels in MM subjects. This result indicates that the $\mathrm{A}$ allele may have a protective effect against disease [160]. However, another study showed no relationship between MM and this gene polymorphism [161].

However, Basmaci et al. demonstrated that the TNF alpha gene polymorphism (-308) GG genotype was more common in the MM group compared with healthy controls [162].

In a recent study, the GG genotype of TNF- $\alpha(-238)$ was shown to be correlated to early progression in MM subjects who had been previously treated with thalidomide- (Thal-) based protocols [163].

Finally, a modification of the concentrations of TNF caused by drugs may play a role in the mechanism of action of the treatments. 
In fact, in MM cells, TNF stimulates the expression of prosurvival elements that are known to cause resistance to apoptotic insults [164-166]. Serum concentration of TNF was related to the disease severity in MM $[167,168]$ and could be a predictive indicator of high symptom burden for subjects undergoing maintenance treatment [169]. Clinical studies have also revealed that Thal analogues, which suppress TNF, are delivered to the tumour microenvironment, augmenting the overall response to TRAILbased treatment $[170,171]$. These data implicate TNF in drug resistance in MM.

Together with the direct effect of lenalidomide (Len) on myeloma growth, both the anti-inflammatory and antiangiogenic effects of Len in the BM environment have been shown to considerably influence the antimyeloma effects of the drug. LEN has an augmented ability to inhibit TNF- $\alpha$ delivered by peripheral blood cells compared with Thal [172].

Nevertheless, Len augmented TNF- $\alpha$ and IL-8 inflammatory cytokines in MM cells that were both sensitive and resistant to Len [173]. These data suggest that Len treatment induces diverse variations depending on the cell type (MM cells or BMSCs). The effects of Len on TNF- $\alpha$ are paradoxical because Len suppresses TNF- $\alpha$ production in the BM environment while inducing it in MM cells. The stimulation of TNF- $\alpha$ secretion by Len in MM cells occurs irrespectively of the proliferative response to Len.

Analogously, monoclonal antibodies (mAbs) targeting several MM cell surface antigens are under clinical investigation [174]. These mAbs exert antimyeloma action through numerous mechanisms, including an effect on TNF. Elotuzumab is an IgG1 anti-SLAMF7 mAb that is under investigation for therapy in MM [175]. The administration of elotuzumab plus lenalidomide augments myeloma cell killing by modifying NK cell function via the upregulation of TNF- $\alpha$. In coculture assays, TNF- $\alpha$ augmented NK cell activation and MM cell death with elotuzumab, and the neutralization of TNF- $\alpha$ reduced NK cell activation and MM cell death [176].

4.12.1. TNF Receptors and TNF Family Members. The efficacy of checkpoint inhibitors has confirmed immunomodulatory agents as an important class of antitumour drugs. An interesting costimulatory immunologic target is CD137, or 4IBB, a component of the TNF receptor superfamily. Binding of 4-1BB provokes an activating signal in CD8 T and NK cells, causing augmented proinflammatory cytokine production, cytolytic activity, and antibody-dependent cellmediated cytotoxicity [177-179].

Targeting 4-1BB with agonistic monoclonal antibody treatment revealed powerful anticancer actions in tumour models.

An anti-41BB mAb, urelumab, a humanized IgG4 mAb, has been used in the clinic. Urelumab is now being investigated in multiple combinatorial protocols, such as those with elotuzumab in MM [180].

4.12.2. B Cell-Activating Factor (BAFF). BAFF is a TNF family component that is principally expressed by some
$\mathrm{T}$ cells, monocytes, and dendritic cells. It is relevant for the preservation of normal $\mathrm{B}$ cell development and is considered a survival factor for activated and immature B cells. It is generated as both a soluble protein and a membrane-bound protein. MM cells express BAFF and its receptors [181].

BAFF has been suggested to promote the growth of MM via an autocrine loop [181].

According to the $\mathrm{B}$ cell maturation stage, BAFF has been confirmed to stimulate the antiapoptotic proteins Bcl-2 and to decrease the proapoptotic protein Bak.

BAFF has been found increased in MM and correlated with both markers of proliferation and angiogenesis [182-184].

Nevertheless, higher concentrations of BAFF ( $>1.38 \mathrm{ng} /$ $\mathrm{ml}$ ) were discovered to be significantly associated with longer OS among MM subjects, which contradicts the data obtained by other authors who proposed BAFF as a potential prognostic factor and a powerful predictor for OS in MM patients due to its correlation with decreased survival $[185,186]$. These contradictory data may be due to the diverse ethnic population evaluated, or to diverse types of treatments. Because BAFF controls and increases adaptive and innate immunity, it may cause improved survival in MM subjects [187]. BAFF has also been recognized as one of the principal survival factors for normal plasma cells such as MM cells.

4.13. IFN. IFN is produced by several cell populations in the innate and adaptive immune system. Secretion is regulated by antigen-presenting cell- (APC-) secreted cytokines, principally IL-18 and IL-12. IL-4, IL-10, and TGF$\beta$ negatively control the secretion of IFN. IFN has a relevant action in defence against intracellular pathogens and in immune-mediated inflammatory responses. It causes cytotoxic activity, controls MHC protein expression and antigen presentation, suppresses cell proliferation and apoptosis, and regulates extension of the immune response by stimulating the activation-induced cell death of $\mathrm{CD} 4 \mathrm{~T}$ cells [188].

The BM environment in MM subjects has been evidenced high levels of cytokines induced by IFN [3]. Furthermore, numerous action effects of these cytokines could be observed.

For example, IP-10 is a chemokine that is produced by several cells in response to IFN. The receptor of IP-10, CXCR3, is present on normal plasma cells, plasmablasts, and MM cells that control plasma cell migration into the BM [189-191], and it regulates the growth and survival of MM cells [192]. IP-10 is produced by MM cell lines and is augmented in the BM environment of MM subjects compared with controls. Remarkably, BM levels of IP-10 correlated with the stage of MM.

Even the efficacy of some therapies used in MM patients could be mediated by IFN.

The direct anti-MM action of Len has been shown to occur via the induction of G1 growth arrest of MM cells [193] and has consistently been associated with a reduction in IFN regulatory factor 4 [194]. 


\section{Anti-Inflammatory Cytokines}

5.1. IL1-Receptor Antagonist (IL-1Ra). IL-lRa is produced and released in response to identical stimuli that cause IL-1 release. IL-IRa neutralizes the activity of IL-1 [195].

In vitro, IL-1Ra has a better effect than dexamethasone on the reduction of IL-6 secretion; maximal IL-6 suppression and apoptosis induction are attained by the addition of both IL-1Ra and dexamethasone. In a clinical study with IL-1 inhibitors, 3 subjects had a minor response to IL-1Ra alone, 5 subjects attained a partial response, and 4 subjects had a minor response after the addition of dexamethasone. The median overall PFS was 37.5 months. Disease stability was achieved in 8 subjects who received treatment for more than 4 years.

In subjects with latent MM who were at risk of evolution to active myeloma, therapy with IL-1 inhibitors reduced the myeloma growth and CRP concentrations in those who responded, with a chronic disease state and an improved PFS [37].

IL-1 receptor-associated kinase 4 (IRAK4) is a serine/ threonine kinase. It has relevant scaffolding and phosphorylation effects on Toll-like receptor (TLR) and IL-1 receptor (IL-1R) signalling pathways. TLR and IL-1R are two cytokine receptors, respectively, which are implicated in inflammatory and immune signalling. Dysregulation of TLR signalling due to IRAK family components has been considered a crucial factor in the initiation of tumours [196].

A combinatorial tactic, targeting IRAK4 and IRAK1, would represent an interesting attempt to decrease cancer progression. Evidence of conjugates that encompass a dual IRAK1/4 kinase inhibitor bound to a Bruton's tyrosine kinase inhibitor resulted in inhibition of NF- $\kappa$ B. In fact, increasing evidence suggests that IRAK inhibitors could be a possible therapy for NF- $\kappa \mathrm{B}$-dependent B cell lymphoproliferative disease Waldenstrom's macroglobulinemia [197, 198].

5.2. IL-4. IL-4 is a cytokine that is produced by basophils, Th2 cells, mast cells, and eosinophils. It is the principal stimulus responsible for the increase in Th2-cells and suppression of Th1 development. It also provokes IgE class switching in B cells, augments the expression of class II MHC molecules in B cells and upregulates B cell receptors. IL- 4 has a relevant action in the regulation of allergic conditions, as well as the protective response against extracellular parasites [35].

IL-4 serum concentrations are significantly increased in $\mathrm{MM}$ subjects, whereas in the BM of MM subjects post-alloSCT, Cao et al. found selectively increased levels of IL-4 [3].

5.3. IL-10. IL-10 is likely the most powerful antiinflammatory cytokine. It is secreted by monocytes/macrophages, NK cells, T and B lymphocytes, and mast cells. As an immunosuppressive cytokine, IL-10 suppresses immune responses by acting on both the innate and adaptive immune system. Therefore, IL-10 can inhibit the secretion of proinflammatory cytokines, antigen presentation, and cell growth [199].
The activities of IL-10 are mediated via the effects of the IL-10 receptor (IL-10R), which includes 2 IL-10R $\alpha$ chains and $2 \mathrm{IL}-10 \mathrm{R} \beta$ chains, on the membrane of the target cell. First, IL-10 reacts with IL-10R $\alpha$ due to the superior affinity of IL-10R $\alpha$ compared with IL-10R $\beta$. This contact successively causes an intermediate complex with a binding site for the IL-10R $\beta$ chain. Successive binding of the IL-10R $\beta$ concludes the active receptor complex [200]. This ligandreceptor connection stimulates Janus kinase-1 and tyro-sine kinase-2, which activate tyrosine phosphorylation and STAT3 [201].

IL-10 has a relevant effect on the tumour microenvironment, as it is present on TAMs and CD8+ T cells. IL-10 can be considered an immunosuppressive cytokine, promoting cancer escape from immune surveillance. Moreover, the autocrine path of TAM-derived IL-10 may reduce the expression of the potentially antitumour IL-12 [202]. However, the immunosuppressive effects of IL-10 are not consistent, and they have been proposed to have some immunostimulating faculties, thus playing a relevant role in anticancer response [203-205]. All the above data support the controversial effects of IL-10 in the cancer microenvironment.

IL-10 can considerably increase the growth of B cells, and it has been implicated in their ultimate differentiation into plasma cells, while Il-10 robustly induces immunoglobulin production by plasma cells [206].

IL-10 has been involved in the genesis of malignant B cell diseases such as chronic lymphocytic leukaemia [207]. Moreover, it seems to function as a proliferation factor for MM cells [208], and augmented serum concentrations of IL-10 have been correlated with an advanced MM stage [209].

In one study, the concentration of IL-10 in serum was measured in subjects with newly diagnosed MM. The best cut-off value for IL-10 for predicting survival was $169.69 \mathrm{pg} / \mathrm{ml}$. The overall response rate was $79.2 \%$ in patients with low IL-10 levels, which was considerably higher than that in subjects with high IL-10 levels (53.3\%). Subjects in the low IL-10 group had superior survival compared with those in the high IL-10 group (3-year PFS rate: 69.3\% versus 13.3\%; 3-year OS rate: $93.6 \%$ versus $51.9 \%$ ). Multivariate analysis confirmed that high serum IL-10 concentrations at diagnosis was an unfavourable factor for PFS and OS [210].

Alexandrakis et al. evaluated serum concentrations of IL10 in MM subjects with diverse stages of disease and correlated them with several angiogenic cytokines (VEGF and Ang-2), and with growth parameters such as BAFF and BM infiltration. IL-10 correlated positively with both angiogenic factors and proliferation markers [211].

Finally, both IL-10 and IL-10R single nucleotide polymorphisms (SNPs) were involved in the pathogenesis of many tumours, including haematologic diseases.

Kasamatsu et al. studied the effect of IL-10 -592C/A, IL10RA I224V, and IL-10RB K47E on the risk of MM and the clinical characteristics of MM. The IL-10RA II genotype was correlated with a haemoglobin concentration lower than that of the IV and VV genotypes. The IL-10 -592 AA genotype was correlated with a superior OS compared to that observed for the CA and CC genotypes. Moreover, differences in survival were observed between subjects treated with 
thalidomide and/or bortezomib and those cured with conventional drugs. Their results suggest that IL-10 and IL-10R gene polymorphisms may not influence the predisposition to $\mathrm{MM}$ but may be correlated with the severity and prognosis of MM [212].

IL-10 increases the proliferation of MM cell lines and MM cells isolated from MM subjects [213]. Gu et al. demonstrated that IL-10 promoted the activation of MM cells by inducing an oncostatin M autocrine loop [214].

Finally, with respect to the pathological action of IL-10 in MM, altered concentrations of IL-10 produced by Treg or MM cells could modulate the host immune response, resulting in a reduction of DC function, by constitutive stimulation of STAT3 in MM [215].

In addition, IL-10 could suppress all-trans retinoic acid(ATRA-) induced proliferation inhibition of MM cells [216].

5.4. IL-11. IL-11 is a glycoprotein-130 (GP-130) cytokine that uses the GP-130 signalling pathway that is shared by several cytokines of the same group. Usually, considered an anti-inflammatory cytokine, IL-11 also functions as a proinflammatory cytokine, supporting its composite role in the immune response. Recently, IL-11 has demonstrated an emergent role in several inflammation-associated tumours. IL-11 is a component of a cytokine group that includes IL-6 and IL-27 [217]. These cytokines are able to activate the Janus kinase (JAK) signal transducer and a STAT3 pathway [218-221].

The binding of IL-11 to its transmembrane coreceptor, IL-11R $\alpha$, has generally been associated with osteoclastogenesis, neurogenesis, adipogenesis, and platelet growth [222]. Nevertheless, recent data indicate the overexpression of IL$11 \mathrm{R} \alpha$ in prostate cancer, gastric cancer, lung cancer, breast cancer, colorectal cancer, and osteosarcoma, suggesting a relevant effect of IL-11 signalling in the link to inflammation and tumours [223].

Regarding MM, one study showed that IL-11 was present in 26 of $121 \mathrm{MM}$ subjects and in 3 of 28 healthy controls at levels of 1.2 and $0.6 \mathrm{pg} / \mathrm{ml}$ [224].

Giuliani et al. has shown that RANK is present in BMSC and endothelial cells but not in MM cells. RANKL did not have a direct effect on MM cell survival, but RANKL treatment caused a relevant augmentation of IL-11 production by both BMSC and endothelial cells. Furthermore, in a coculture model, MM cells upregulated IL-11 production by BMSC and endothelial cells via cell-to-cell contact. However, the presence of the RANK-Fc that blocks the RANK/RANKL interaction suppressed production of IL-11 [225].

The contribution of osteocytes in MM-induced osteoclast (OCL) development and bone lesions remains undetermined. Osteocytes control bone remodelling as a consequence of their cell death-activating OCL recruitment. In another study, the authors discovered that the quantity of viable osteocytes was reduced in MM subjects and negatively related to the number of OCLs. Furthermore, the MM subjects with lytic lesions had significantly fewer viable osteocytes than those without lesions, probably because of augmented apoptosis. A microarray analysis revealed that MM cells modified the transcriptional profiles of preosteocytes by increasing the secretion of osteoclastogenic interleukins such as IL-11 and augmenting their proosteoclastogenic abilities. Finally, the osteocyte presence of IL-11 was higher in MM subjects with than those without lytic lesions [226].

5.5. TGF- $\beta$. TGF- $\beta$ is present as 3 isoforms in mammals: TGF-1, TGF-2, and TGF-3. Platelets are a copious source of TGF [227]. It is produced as a protein complex that requires activation for its biological activity. Once activated, the TGF ligands control cellular processes via the binding of two highaffinity cell-surface receptors, the type I receptor (T RI) and type II receptor (T RII), both of which contain a serine/threonine protein kinase in their intracellular domains [228]. The activated T RI phosphorylates the receptor-activated transcription factors, Smad2/3, which then bind to the common Smad4, translocate into the nucleus, and interact with transcription factors (E2F, Runx1), corepressors (SnoN, c-Ski, SnoN, and TGIF), and coactivators (p300, CBP), to control the transcription of TGF-responsive genes [229, 230].

TGF- $\beta$ is a powerful regulatory cytokine with different effects on haemopoietic cells. This cytokine has a relevant role in inflammation and in inhibition of self-targeted responses [231, 232].

TGF- $\beta$ generally acts to reduce immunoglobulin secretion by B cells [233].

Throughout haematopoiesis, the TGF pathway is a powerful negative regulator of growth-activating differentiation and, when required, apoptosis. In haematologic tumours comprising myeloproliferative disorders, leukaemia, lymphomas, and MM, resistance to these effects of TGF- $\beta$ occurs. Mechanisms underlying this resistance involve interference in the pathway by oncoproteins. These modifications define a tumour suppressor role for TGF in haematologic diseases. However, increased concentrations of TGF can cause myelofibrosis.

In MM, opposition to the homeostatic effects of TGF- $\beta$ signalling arises, perhaps via inadequate trafficking of $\mathrm{T} \beta \mathrm{RI}$ and T $\beta$ RII to the cell surface. As a consequence, both plasma cells and BM stromal cells from MM subjects produce higher concentrations of TGF- $\beta$ compared with plasma cells from healthy controls [234], participating in the immune alteration present in MM.

Notably, a T $\beta$ RI inhibitor or TGF- $\beta$-neutralizing antibodies can prevent VEGF and IL-6 production and reduce MM cell proliferation and cell adhesion to BMSCs.

Functionally, the reestablishment of T $\beta$ III expression in MM cells drastically reduced cell proliferation. In a reciprocal manner, shRNA-mediated silencing of endogenous T $\beta$ RIII expression augmented cell proliferation. Although apoptosis was not modified, $\mathrm{T} \beta \mathrm{RIII}$ reduced growth by stimulating the cyclin-dependent kinase inhibitors p21 and p27. Moreover, $\mathrm{T} \beta \mathrm{RIII}$ controlled MM cell adhesion, augmenting homotypic MM cell adhesion while reducing MM heterotropic adhesion to BM stromal cells [235].

TGF- $\beta$ is also relevant to hypoxia-induction of MM cancer stem cell-like side populations [236].

Regarding bone disease in MM subjects, TGF- $\beta$ is a powerful inhibitor of terminal $\mathrm{OB}$ mineralization [237]. It is 
secreted by osteocytes and OBs and copiously accumulated in bone matrices in a latent form. It is discharged from bone matrices after bone resorption and activated by matrix metalloproteinases produced by OCs. As osteoclastic bone resorption is augmented in MM, TGF- $\beta$ seems to be plentiful in MM bone lytic lesions, and it may have a relevant role in bone formation altered by MM.

Moreover, TGF- $\beta$-reduced OB differentiation from BM stromal cells and MC3T3-E1 preosteoblastic cells, as well as reduced adipogenesis from $\mathrm{C} 3 \mathrm{H} 10 \mathrm{~T} 1 / 2$ immature mesenchymal cells, supported a differentiation arrest by TGF- $\beta$. Molecules that were able to inhibit TGF- $\beta$ type I receptor kinase, such as Ki26894 and SB431542, powerfully augmented $\mathrm{OB}$ differentiation from $\mathrm{BM}$ stromal as well as MC3T3-E1 cells. The reduction of TGF- $\beta$ was capable of reestablishing $\mathrm{OB}$ differentiation that had been reduced by MM cell conditioned medium as well as BM plasma from MM subjects. Remarkably, TGF- $\beta$ reduction accelerated OB differentiation in an analogous manner by reducing MM cell proliferation. The effects of anti-MM were due solely to terminally differentiated OBs. Moreover, the reduction of TGF- $\beta$ was capable of reducing MM cell proliferation within the BM while avoiding bone damage in MM-bearing animal models. Research has confirmed that TGF- $\beta$ reduction liberates stromal cells from their differentiation inhibition by MM. TGF- $\beta$ accelerates the formation of terminally differentiated $\mathrm{OBs}$ that increase the sensitivity of MM cells to anti-MM drugs to overwhelm the drug resistance due to stromal cells [237].

Although TGF- $\beta$ increases the growth of osteoblast progenitors, it strongly reduces later phases of osteoblast maturation and suppresses matrix mineralization. Reduction of TGF- $\beta$ signalling can become a novel therapeutic method against MM [237].

TGF- $\beta$ could also be implicated in chemoresistance. Frassanito et al. showed that BM cancer-associated fibroblasts (CAFs) from bort-resistant subjects are insensitive to bort and defend RPMI8226 and subject plasma cells against bort-induced apoptosis [238]. Bort stimulates CAFs to secrete high concentrations of TGF- $\beta$. In the syngeneic 5T33 MM model, bort therapy caused an increase in LC3- $\mathrm{II}^{+}$ CAFs. TGF- $\beta$ facilitated bort-induced autophagy, and its block by LY2109761, a selective T $\beta$ RI/II inhibitor, decreased the presence of LC3-II and p-Smad2/3 and induced apoptosis in bort-resistant CAFs. Bort and LY2109761 synergistically provoked apoptosis of RPMI8226 cocultured with bortresistant CAFs [239].

Progress in the TGF signalling field should reveal new possibilities for the treatment of MM [239].

\section{Mediators of Cytokines}

6.1. Heat-Shock Proteins. Heat-shock proteins (HSPs) are believed to be highly conserved proteins and a danger signal that chaperone, fold, and transport proteins when cells are subjected to numerous stresses. Augmented production of extracellular HSPs causes the liberation of proinflammatory cytokines by macrophages and monocytes. This provokes upregulated expression of antigen-presenting molecules on immature DCs and changes the ability of these cells to participate in the immune response [240]. Furthermore, HSPs represent the endogenous signals that stimulate DCs as they translocate antigen to the cytosol in DCs [241]. These actions can be either protective, such as after a cellular insult, or damaging because they can lead to disproportionate inflammation [242].

Under nonstressed situations, chaperones are implicated in numerous crucial biochemical activities. They support the exact folding of the polypeptide as translation progresses, control the transport of proteins across subcellular membranes, influence the turnover of folded proteins, and contribute to the posttranslational control of signalling proteins, avoiding their irregular aggregation and helping client proteins avoid destruction via the ubiquitinproteasome pathway.

Despite their name, most of these substances are ubiquitously present under physiological situations. However, their synthesis is augmented by a large range of stressful situations beyond heat shock, and their presence has been found to be significantly augmented in numerous tumours (both solid cancers and haematologic diseases) [243, 244].

The HSP90 protein family comprises HSP90a (HSPC1), HSP90b (HSPC3), and gp96 (HSP4).

The heat-shock protein $90 \mathrm{kDa}$ appears to be one of the most interesting because it interacts with several client proteins that are implicated in numerous relevant regulatory pathways, such as cell cycle control and defence against apoptosis [245, 246]. Furthermore, its action appears to be essential for cancer cells to preserve an abnormal homeostasis, defending themselves against the microenvironment, which is acidotic, hypoxic, and nutrient-deprived [247, 248].

Tumour cell apoptosis is controlled by HSP90, principally through its action on TNF-mediated signalling pathways [249] and on nuclear factor- $\kappa \mathrm{B}$ [250]. It has also been observed that some HSP90 clients, such as p53 and SRC tyrosine kinase, often assume oncogenic mutations that lead to an abnormal interaction with chaperones [251]. This molecular connection appears to inhibit the process of p53-ubiquitylation and enzymatic degradation, altering cell cycle control [252, 253].

HSP90 is overexpressed in MM and promotes tumour cell survival. Augmented HSP90 protein concentrations were demonstrated in IL- 6 transgenic mice that display increased IL-6 concentrations. Similarly, it has been shown that IL-6 can provoke augmented concentrations of HSP90 in numerous cell types. Moreover, it has been established that STAT3 and CCAAT/enhancer-binding protein $\beta(\mathrm{CEBP} \beta)$ bind to and activate the HSP90 $\beta$ promoter and augment HSP90 levels [254, 255].

Pharmacologic blockade of HSP90 has been found to provoke MM cell death [256, 257].

Numerous studies have demonstrated the effectiveness of HDAC inhibitors in curing MM [258, 259]. Vorinostat increased $\mathrm{p} 21^{\mathrm{WAF} 1}$ by changing the methylation and acetylation of core histones and by impeding the enzyme accessibility of DNase I in the promoter region of MM cells [260].

Panobinostat, a pan-HDAC inhibitor, with Bor and dexamethasone, has attained long progression-free survival 
in MM subjects. Panobinostat reduced MM cell proliferation by destroying protein phosphatase 3 catalytic subunit a (PPP3CA), a catalytic subunit of calcineurin. This modification was proposed to be mediated by blocking the function of heat-shock protein 90 due to HDAC6 inhibition [261].

Xie et al. produced an MM cell line, J558HSP, presenting endogenous P1A tumour antigen and a transgenic form of membrane-bound HSP70 and heat-shocked J558HS expressing cytoplasmic HSP70, and purified EXOHSP and EXOHS from the J558HSP and J558HS tumour cell culture supernatant. They confirmed that EXOHSP was able to cause maturation of DCs and to stimulate Th1 cell responses [262].

Jung et al. examined whether treatment of MM cells with a STAT3 inhibitor (JSI-124) and/or Bor before loading into DCs could influence DC function. The therapy with JSI-124 and Bor caused the highest expression of HSP 90 and the lowest expression of p-STAT3 in dying MM cells. DCs loaded with JSI-124 and Bor produced MM-specific cytotoxic T lymphocytes (CTLs) [263].

6.2. Leptin and Resistin. Accumulating evidence supports a role for obesity in the genesis of MM [264]. As adipose tissue increases in obesity, the quantities of anti-inflammatory adipokines are reduced and the quantities of proinflammatory adipokines with oncogenic capability, such as resistin, leptin, visfatin, and chemerin, are augmented [265].

Leptin is a crucial regulator of energy expenditure and caloric intake, and numerous studies have correlated obesity to altered leptin metabolism [266].

Moreover, a correlation between leptin and the immune system has been discovered, and a correlation between plasma leptin concentrations and the TNF- $\alpha$ system has been observed in obese patients [267, 268].

Hofmann et al. found that MM subjects had higher concentration of leptin in comparison to controls, although this difference did not achieve statistical significance. They subsequently concluded that leptin concentrations were not associated with MM risk [269].

However, in another study, leptin was elevated in MM subjects compared with the healthy controls. A significant positive correlation was discovered between IgG levels and leptin. Moreover, a significant difference in leptin concentration has been observed between stage I and stage II [270].

Finally, Alexandrakis et al. confirmed an increase of leptin levels in newly diagnosed MM patients, and they found a decrease in leptin following treatment [271].

Resistin was initially identified as a molecule that provoked insulin resistance and produced hyperglycaemia without influencing peripheral insulin sensitivity [272].

Regarding resistin and MM, Considine et al. discovered that the concentration of resistin was lower in MM subjects with respect to the control group, but this difference did not attain significance. Moreover, they found insignificant correlations between resistin and IgG concentrations and between BM plasma cells and resistin in MM patients. Only LDH levels had a negative correlation with the resistin level [273].

\section{Discussion}

7.1. A New Therapeutic Target: Cytokines. The role of cytokines in the pathogenesis and progression of neoplastic diseases is now undeniable. Consequently, we could employ cytokines as therapeutic targets with numerous benefits. First, proteins that regulate the inflammatory process can be suppressed. Moreover, cytokines are well validated in animal models utilizing genetic models such as knockout mice or neutralizing antibodies.

Nevertheless, the disadvantages of cytokine treatment derive from the same properties. Cytokines influence numerous processes in parallel. Moreover, they have redundancy, and the effects attained by suppressing one specific cytokine can be balanced by others. Alterations of the cytokine system may lead to a modulated immune response. For example, the suppression of proinflammatory cytokines can cause compromised host defence against infections, while the suppression of regulatory cytokines can provoke autoimmunity or tissue damage. Moreover, the fabrication of biologics is still a high-priced process since their manufacturing requires sterile conditions and multiple phases of purification, and recombinant cytokines have a restricted half-life, necessitating special storage conditions [274].

However, numerous drugs utilized in MM therapy have an effect on cytokines. Len exerts cytotoxic actions on MM cells and has anti-inflammatory, immunomodulatory, and antiangiogenic actions on BM accessory cells. Its immunomodulatory actions comprise the stimulation of subsets of T cells to secrete Th1 cytokines such as IL- 2 and IFN- $\gamma$ while suppressing the production of Th2 cytokines such as IL-6 and TNF- $\alpha$ [275-277].

Of interest could be the data showing transient inflammatory reactions in a subpopulation of MM subjects during Len plus dexamethasone treatment. Adjustment of Th1 and Th2 cytokine secretion by Len may participate in the transitory inflammatory reaction in MM patients [278].

Finally, considering inflammation and cytokines as possible targets, it is possible to consider the possibility of introducing new drugs in MM therapy.

Cyclooxygenase 2 (COX-2) is an inflammationassociated enzyme. Generally, Cox-2 is not present in cells, but its expression can be increased in an environment including growth factors, cytokines, and inflammatory molecules [279].

There are few studies reporting Cox-2 expression in MM subjects [280-282]. Moreover, other papers showing Cox-2 expression in MM cell lines are contradictory [283, 284].

It has been suggested that chronic inflammation is linked to aberrant angiogenesis [19]. Khan et al. demonstrated a positive correlation between angiogenic factors and cyclooxygenase [285].

Targeting COX-2 by utilizing inhibitors that establish antiangiogenic and antitumour effects could be used as a novel treatment approach for MM therapy.

7.2. Multiple Myeloma and Inflammation: A Nonunique Connection. However, the relationship between inflammation and cancer and between cytokines and neoplasms is 
certainly less linear and defined than previously thought, and it is very different than that observed for other pathophysiological conditions such as ageing [286, 287].

The immune system can defend against tumours, and several cytokines predict long-term survival for subjects with advanced cancer.

Proinflammatory cytokines such as IL-6 and IL-1 are believed to be indispensable for cancer progression, and anti-inflammatory drugs have been proposed to treat tumours. Nevertheless, anti-inflammatory therapies may theoretically reduce protective antitumour immunity. In fact, although inflammation is commonly deemed to be cancer promoting, few studies in breast, bladder, and colorectal cancer suggest that cancer infiltration by inflammatory cells may be correlated with a better prognosis [288-290].

As previously shown, proinflammatory cytokines can have both pro and anticancer activities, while cytokines with potent anti-inflammatory activity may strongly favour the growth of tumours. To bring together these contrasting views, it is possible to suggest that inflammation, when guided by cancer-specific Th1 cells, may inhibit tumour onset and progression. In a Th1 microenvironment, proinflammatory cytokines (e.g., IL-6, IL- $1 \alpha$, and IL- $1 \beta$ ) may contribute to tumour eradication by attracting leucocytes from the circulation and by increasing $\mathrm{CD} 4{ }^{+} \mathrm{T}$ cell activity.

Approaches to fight cancer should be based on promoting rather than reducing the immune response against tumours. Thus, it is essential to better comprehend the relationship between immune cells, inflammation, and cancer.

MM is typically exemplified by a desynchronized cytokine system with an increase in inflammatory cytokines.

Ben-Sasson et al. evaluated locally produced cytokines throughout the primary immune response against MM in mice [291]. Strikingly, efficacious tumour immunosurveillance due to tumour-specific CD4 ${ }^{+} \mathrm{T}$ cells was consistently related to increased local concentrations of both proinflammatory (IL-6, IL- $1 \alpha$, and IL- $1 \beta$ ) and Th1-associated cytokines (IL-2, IL-12, and IFN- $\gamma$ ).

Tumour suppression is attained by the cooperation of cancer-specific Th1 cells and cancer-infiltrating, antigenpresenting macrophages. Th1 cells provoke the production of IL- 6 and IL- $1 \beta$ by macrophages. Th1-derived IFN- $\gamma$ is known to cause macrophage cytotoxicity to tumour cells and to stimulate macrophages to produce the angiostatic factors CXCL10/IP-10 and CXCL9/MIG. Thus, inflammation, when guided by cancer-specific Th1 cells, may inhibit rather than stimulate tumours.

To confirm this statement, Haabeth et al. utilized a technique to measure locally produced cytokines during primary anticancer immune responses in mice [292]. Employing this approach, they recognized a core of nine cytokines that consistently correlated with efficacious tumour suppression: IL-12p70, IFN- $\gamma$, IL- $1 \alpha$, IL-1 $\beta$, IL-2, IL-3, IL-6, CXCL10, and CXCL9. The finding that IL-12 and IFN $-\gamma$ are consistently associated with tumour rejection is coherent with a Th1 polarization of the immune response, which is generally believed to be advantageous for immunological control of tumours $[293,294]$. In contrast, the proinflammatory cytokines IL- 6 , IL- $1 \alpha$, and IL- $1 \beta$ may appear more unexpectedly as chronic inflammation related to the tumour [295-298].

The finding that increased concentrations of IL-1 were connected with efficacious tumour immune-surveillance is of special interest. IL-1 is a canonical proinflammatory cytokine, and it acts as a positive feedback loop in inflammation. IL-1 has been demonstrated to increase the growth and differentiation of CD4 ${ }^{+} \mathrm{T}$ cells and to stimulate macrophage tumouricidal action in vitro [299]. Significantly, IL-1 $\beta$ production by macrophages is reliant on activation of the inflammasome, a cytosolic molecular complex responsible for producing active IL- $1 \beta$ by cleaving the inoperative precursor. The inflammasome acts as a sentinel by identifying pathogens and danger signals [300]. In cancer immunosurveillance, the type of endogenous danger signals identified by the inflammasome remain to be clarified, although a role for ATP produced by necrotic tumour cells has been proposed [301].

Hence, caution should be used when considering therapies that target factors with pro or anti-inflammatory activity. Drugs that may reduce the tumour-suppressive Th1-driven inflammatory immune response should be avoided.

New perspectives concerning intervention seem possible, and the use of nanotechnology could be a powerful approach to the use of cytokines in the prevention and treatment of cancer [302-304]. A better understanding of the relationship between inflammation and myeloma will ensure more effective therapeutic interventions.

\section{Conflicts of Interest}

The authors declare that they have no conflicts of interest.

\section{Authors' Contributions}

Caterina Musolino, Alessandro Allegra, and Sebastiano Gangemi contributed equally to this work.

\section{References}

[1] R. A. Kyle and S. V. Rajkumar, "Multiple myeloma," The New England Journal of Medicine, vol. 351, pp. 1860-1873, 2004.

[2] L. M. Coussen and Z. Werb, "Inflammation and cancer," Nature, vol. 420, pp. 860-867, 2002.

[3] Y. Cao, T. Luetkens, S. Kobold et al., "The cytokine/ chemokine pattern in the bone marrow environment of multiple myeloma patients," Experimental Hematology, vol. 38, pp. 860-867, 2010.

[4] M. Hallek, P. L. Bergsagel, and K. C. Anderson, "Multiple myeloma: increasing evidence for a multistep transformation process," Blood, vol. 91, pp. 3-21, 1998.

[5] I. Van Riet, "Homing mechanisms of myeloma cells," Pathologie-biologie, vol. 47, pp. 98-108, 1999.

[6] M. Kawano, T. Hirano, T. Matsuda et al., "Autocrine generation and requirement of BSF-2/IL- 6 for human multiple myelomas," Nature, vol. 332, pp. 83-85, 1988.

[7] A. Zlotnik, "Chemokines and cancer," International Journal of Cancer, vol. 119, pp. 2026-2029, 2006. 
[8] B. Zdzisinska, A. Bojarska-Junak, A. Dmoszynska, and C. Kandefer-Szerszen, "Abnormal cytokine production by bone marrow stromal cells of multiple myeloma patients in response to RPMI8226 myeloma cells," Archivum Immunologiae et Therapiae Experimentalis (Warsz), vol. 56, pp. 207-221, 2008.

[9] D. Raman, P. J. Baugher, Y. M. Thu, and A. Richmond, "Role of chemokines in tumor growth," Cancer Letters, vol. 256, pp. 137-165, 2007.

[10] J. W. Lee, H. Y. Chung, L. A. Ehrlich et al., "IL-3 expression by myeloma cells increases both osteoclast formation and growth of myeloma cells," Blood, vol. 103, pp. 2308-2315, 2004.

[11] A. Pellegrino, R. Ria, G. Di Pietro et al., "Bone marrow endothelial cells in multiple myeloma secrete CXC-chemokines that mediate interactions with plasma cells," British Journal of Haematology, vol. 129, pp. 248-256, 2005.

[12] K. Podar, Y. T. Tai, F. E. Davies et al., "Vascular endothelial growth factor triggers signaling cascades mediating multiple myeloma cell growth and migration," Blood, vol. 98, pp. 428-435, 2001.

[13] K. Podar, Y. T. Tai, B. K. Lin et al., "Vascular endothelial growth factor-induced migration of multiple myeloma cells is associated with beta 1 integrin- and phosphatidylinositol 3-kinase-dependent PKC alpha activation," The Journal of Biological Chemistry, vol. 277, pp. 7875-7881, 2002.

[14] A. Vacca, D. Ribatti, A. M. Roccaro, R. Ria, L. Palermo, and F. Dammacco, "Bone marrow angiogenesis and plasma cell angiogenic and invasive potential in patients with active multiple myeloma," Acta Haematologica, vol. 106, pp. 162169, 2001.

[15] S. Niida, M. Kaku, H. Amano et al., "Vascular endothelial growth factor can substitute for macrophage colonystimulating factor in the support of osteoclastic bone resorption," The Journal of Experimental Medicine, vol. 190, pp. 293-298, 1999.

[16] Y. Tanaka, M. Abe, M. Hiasa et al., "Myeloma cell-osteoclast interaction enhances angiogenesis together with bone resorption: a role for vascular endothelial cell growth factor and osteopontin," Clinical Cancer Research, vol. 13, pp. 816823, 2007.

[17] J. H. Dewald, F. Colomb, M. Bobowski-Gerard, S. GrouxDegroote, and P. Delannoy, "Role of cytokine-induced glycosylation changes in regulating cell interactions and cell signaling in inflammatory diseases and cancer," Cell, vol. 5, no. 43, 2016.

[18] L. Sedlarikova, K. Sadílková, L. Kubiczková, R. Hájek, and S. Sevčíková, "Cytokine profiles of multiple myeloma and Waldenstrom macroglobulinemia," Klinická Onkologie, vol. 27, no. 1, pp. 18-23, 2014.

[19] O. Mehtap, E. B. Atesoglu, P. Tarkun, A. Hacihanefioglu, I. Dolasik, and M. M. Musul, "IL-21 and other serum proinflammatory cytokine levels in patients with multiple myeloma at diagnosis," Journal of Postgraduate Medicine, vol. 60, no. 2, pp. 141-144, 2014.

[20] A. K. Abbas, K. M. Murphy, and A. Sher, "Functional diversity of helper T lymphocytes," Nature, vol. 383, pp. 787-793, 1996.

[21] T. R. Mosmann and S. Sad, "The expanding universe of T-cell subsets: Th1, Th2 and more," Immunology Today, vol. 17, no. 3, pp. 138-146, 1996.
[22] H. Park, Z. Li, X. O. Yang et al., "A distinct lineage of CD4 T cells regulated tissue inflammation by producing interleukin 17," Nature Immunology, vol. 6, no. 11, pp. 1133-1141, 2005.

[23] E. Bettelli, M. Oukka, and V. K. Kuchroo, "T(H)-17 cells in the circle of immunity and autoimmunity," Nature Immunology, vol. 8, no. 4, pp. 345-350, 2007.

[24] S. Sakaguchi, M. Ono, R. Setoguchi et al., "Foxp3+ CD25+ $\mathrm{CD} 4+$ natural regulatory $\mathrm{T}$ cells in dominant self-tolerance and autoimmune disease," Immunology Reviews, vol. 212, pp. 8-27, 2006.

[25] M. Ryba-Stanislawowska, M. Skrzypkowska, M. Myśliwiec, and J. Myśliwska, "Loss of the balance between CD4(+)Foxp3(+) regulatory T cells and CD4(+) IL17A(+) Th17 cells in patients with type 1 diabetes," Human Immunology, vol. 74, no. 6, pp. 701-707, 2013.

[26] M. C. Boissier, E. Assier, G. Falgarone, and N. Bessis, "Shifting the imbalance from Th1/Th2 to Th17/treg: the changing rheumatoid arthritis paradigm," Joint, Bone, Spine, vol. 75, no. 4, pp. 373-375, 2008.

[27] X. Cheng, X. Yu, Y. J. Ding et al., “The Th17/Treg imbalance in patients with acute coronary syndrome," Clinical Immunology, vol. 127, no. 1, pp. 89-97, 2008.

[28] Y. Zhang, L. X. Song, X. Zhang, C. Xiao, and C. K. Chang, "Function of peripheral blood Th17 cells in patients with multiple myeloma," Zhongguo Shi Yan Xue Ye Xue Za Zhi, vol. 21, no. 5, pp. 1187-1189, 2013.

[29] P. Feng, R. Yan, X. Dai, X. Xie, H. Wen, and S. Yang, "The alteration and clinical significance of Th1/Th2/Th17/Treg cells in patients with multiple myeloma," Inflammation, vol. 38, no. 2, 2015.

[30] M. Wang, P. Chen, Y. Jia et al., "Elevated Th22 as well as Th17 cells associated with therapeutic outcome and clinical stage are potential targets in patients with multiple myeloma," Oncotarget, vol. 6, no. 20, pp. 1795817967, 2015.

[31] T. Atanackovic, Y. Cao, T. Luetkens et al., " $\mathrm{CD} 4^{+} \mathrm{CD} 25^{+}$ $\mathrm{FOXP}^{+} \mathrm{T}$ regulatory cells reconstitute and accumulate in the bone marrow of patients with multiple myeloma following allogeneic stem cell transplantation," Haematologica, vol. 3, pp. 423-430, 2008.

[32] R. H. Prabhala, P. Neri, J. Bae et al., "Dysfunctional T regulatory cells in multiple myeloma," Blood, vol. 1, pp. 301-304, 2006.

[33] H. Huang, Y. Luo, Y. Liang et al., " $\mathrm{CD} 4^{+} \mathrm{CD} 25^{+}$cells in multiple myeloma related renal impairment," Scientific Reports, vol. 5, article 16565, 2015.

[34] C. Gabay, C. Lamacchia, and G. Palmer, "IL-1 pathways in inflammation and human diseases," Nature Reviews Rheumatology, vol. 6, pp. 232-241, 2010.

[35] M. Akdis, S. Burgler, R. Crameri et al., "Interleukins, from 1 to 37 , and interferon- $\gamma$ : receptors, functions, and roles in diseases," The Journal of Allergy and Clinical Immunology, vol. 127, pp. 701-721, 2011.

[36] Y. Xiong, K. A. Donovan, M. P. Kline et al., "Identification of two groups of smoldering multiple myeloma patients who are either high or low producers of interleukin-1," Journal of Interferon \& Cytokine Research, vol. 26, pp. 8395, 2006.

[37] J. A. Lust, M. Q. Lacy, S. R. Zeldenrust et al., "Induction of a chronic disease state in patients with smoldering or indolent multiple myeloma by targeting interleukin $1 \beta$-induced 
interleukin 6 production and the myeloma proliferative component," Mayo Clinic Proceedings, vol. 84, pp. 114122, 2009.

[38] J. A. Lust, M. Q. Lacy, S. R. Zeldenrust et al., "Reduction in C-reactive protein indicates successful targeting of the IL-1/IL-6 axis resulting in improved survival in early stage multiple myeloma," American Journal of Hematology, vol. 91, pp. 571-574, 2016.

[39] A. X. H. Goh, S. Bertin-Maghit, S. P. Yeo et al., "A novel human anti-interleukin- $1 \beta$ neutralizing monoclonal antibody showing in vivo efficacy," MAbs, vol. 6, no. 3, pp. 765773, 2014.

[40] M. de la Rosa, S. Rutz, H. Dorninger, and A. Scheffold, "Interleukin-2 is essential for CD4+ CD25+ regulatory T cell function," European Journal of Immunology, vol. 34, pp. 2480-2488, 2004.

[41] D. M. Benson Jr, C. E. Bakan, A. Mishra et al., "The PD-1/ PD-L1 axis modulates the natural killer cell versus multiple myeloma effect: a therapeutic target for CT-011, a novel monoclonal anti-PD-1 antibody," Blood, vol. 116, pp. 22862294, 2010.

[42] R. Zeiser, H. Bertz, A. Spyridonidis, L. Houet, and J. Finke, "Donor lymphocyte infusions for multiple myeloma: clinical results and novel perspectives," Bone Marrow Transplantation, vol. 34, pp. 923-928, 2004.

[43] S. Szmania, B. Balasa, P. Malaviarachi et al., "CS1 is expressed on myeloma cells from early stage, late stage, and drug-treated multiple myeloma patients, and is selectively targeted by the huluc63 antibody," Blood, vol. 108, p. 660a, 2006.

[44] J. Shi, G. Tricot, S. Szmania et al., "Infusion of haploidentical killer immunoglobulin-like receptor ligand mismatched NK cells for relapsed myeloma in the setting of autologous stem cell transplantation," British Journal of Haematology, vol. 143, pp. 641-653, 2008.

[45] S. Sarkar, W. T. V. Germeraad, K. M. A. Rouschop et al., "Hypoxia induced impairment of NK cell cytotoxicity against multiple myeloma can be overcome by IL-2 activation of the NK cells," PLoS One, vol. 8, no. 5, article e64835, 2013.

[46] J. Wolf, S. Rose-John, and C. Garbers, "Interleukin-6 and its receptors: a highly regulated and dynamic system," Cytokine, vol. 70, pp. 11-20, 2014.

[47] T. Hirano, "Revisiting the 1986 molecular cloning of interleukin 6," Frontiers in Immunology, vol. 5, p. 456, 2014.

[48] I. Tinhofer, I. Marschitz, T. Henn, A. Egle, and R. Greil, "Expression of functional interleukin 15 receptor and autocrine production of interleukin 15 as mechanism of tumor propagation in multiple myeloma," Blood, vol. 95, pp. 610618, 2000.

[49] M. G. Alexandrakis, F. H. Passam, A. Boula et al., "Relationship between circulating serum soluble interleukin-6 receptor and the angiogenic cytokines basic fibroblast growth factor and vascular endothelial growth factor in multiple myeloma," Annals of Hematology, vol. 82, pp. 1923, 2003.

[50] G. Tsirakis, C. A. Pappa, M. Kaparou et al., "The relationship between soluble receptor of interleukin-6 with angiogenic cytokines and proliferation markers in multiple myeloma," Tumor Biology, vol. 34, pp. 859-864, 2013.

[51] T. T. Pelliniemi, K. Irjala, K. Mattila et al., "Immunoreactive interleukin- 6 and acute phase proteins as prognostic factors in multiple myeloma. Finnish Leukemia Group," Blood, vol. 85, pp. 765-771, 1995.

[52] S. Joshi, N. Gupta, R. Khan et al., "Interrelationship between angiogenesis, inflammation and oxidative stress in Indian patients with multiple myeloma," Clinical \& Translational Oncology, vol. 18, no. 2, pp. 132-137, 2016.

[53] T. Matthes, B. Manfroi, and B. Huard, "Revisiting IL-6 antagonism in multiple myeloma," Critical Reviews in Oncology/ Hematology, vol. 105, pp. 1-4, 2016.

[54] A. Markham and T. Patel, "Siltuximab: first global approval," Drugs, vol. 74, no. 10, pp. 1147-1152, 2014.

[55] S. Bagcchi, "Siltuximab in transplant-ineligible patients with myeloma," The Lancet Oncology, vol. 15, no. 8, article e309, 2014.

[56] S. K. Thomas, A. Suvorov, L. Noens et al., "Evaluation of the QTc prolongation potential of a monoclonal antibody, siltuximab, in patients with monoclonal gammopathy of undetermined significance, smoldering multiple myeloma, or low-volume multiple myeloma," Cancer Chemotherapy and Pharmacology, vol. 1, pp. 35-42, 2014.

[57] S. Kanoh and B. K. Rubin, "Mechanisms of action and clinical application of macrolides as immunomodulatory medications," Clinical Microbiology Reviews, vol. 23, no. 3, pp. 590-615, 2010.

[58] M. Nakamura, Y. Kikukawa, M. Takeya, H. Mitsuya, and H. Hata, "Clarithromycin attenuates autophagy in myeloma cells," International Journal of Oncology, vol. 37, pp. 815820, 2010.

[59] S. Moriya, X. F. Che, S. Komatsu et al., "Macrolide antibiotics block autophagy flux and sensitize to bortezomib via endoplasmic reticulum stress-mediated CHOP induction in myeloma cells," International Journal of Oncology, vol. 42, no. 5, pp. 1541-1550, 2013.

[60] B. G. M. Durie, "Clarithromycin (Biaxin) as primary treatment for myeloma," Blood, vol. 90, no. 279a, abstract supplement 1, 1997.

[61] P. Musto, A. Falcone, G. Sanpaolo, C. Bodenizza, M. Carotenuto, and A. M. Carella, "Inefficacy of clarithromycin in advanced multiple myeloma: a definitive report," Haematologica, vol. 87, no. 6, pp. 658-659, 2002.

[62] T. C. Morris, L. Ranaghan, and J. Morrison, "Phase II trial of clarithromycin and pamidronate therapy in myeloma," Medical Oncology (Northwood, London, England), vol. 18, no. 1, pp. 79-84, 2001.

[63] A. K. Stewart, S. Trudel, B. M. Al-Berouti, D. M. Sutton, and J. Meharchand, "Lack of response to short-term use of clarithromycin (BIAXIN) in multiple myeloma," Blood, vol. 93, no. 12, p. 4441, 1999.

[64] P. Moreau, A. Huynh, T. Facon et al., "Lack of efficacy of clarithromycin in advanced multiple myeloma. Intergroupe Français du Myélome (IFM)," Leukemia, vol. 13, no. 3, pp. 490-491, 1999.

[65] R. Burger, "Impact of interleukin-6 in hematological malignancies," Transfusion Medicine and Hemotherapy, vol. 40, no. 5, pp. 336-343, 2013.

[66] M. Sakamoto, K. Mikasa, T. Majima et al., "Anti-cachectic effect of clarithromycin for patients with unresectable nonsmall cell lung cancer," Chemotherapy, vol. 47, pp. 444451, 2001.

[67] I. B. McInnes, A. Kavanaugh, A. B. Gottlieb et al., "Efficacy and safety of ustekinumab in patients with active psoriatic 
arthritis: 1-year results of the phase 3, multicenter, doubleblind, placebo-controlled PSUMMIT 1 trial," Lancet, vol. 382, pp. 780-789, 2013.

[68] M. J. Brunda, L. Luistro, R. R. Warrier et al., "Antitumor and antimetastatic activity of interleukin 12 against murine tumors," The Journal of Experimental Medicine, vol. 178, pp. 1223-1230, 1993.

[69] M. P. Colombo and G. Trinchieri, "Interleukin-12 in antitumor immunity and immunotherapy," Cytokine \& Growth Factor Reviews, vol. 13, pp. 155-168, 2002.

[70] M. J. Smyth, M. Taniguchi, and S. E. Street, "The anti-tumor activity of IL-12: mechanisms of innate immunity that are model and dose dependent," Journal of Immunology, vol. 165, pp. 2665-2670, 2000.

[71] I. Airoldi, E. Di Carlo, C. Cocco et al., "Endogenous IL-12 triggers an antiangiogenic program in melanoma cells," Proceedings of the National Academy of Sciences of the United States of America, vol. 104, pp. 3996-4001, 2007.

[72] S. Dias, R. Boyd, and F. Balkwill, "IL-12 regulates VEGF and MMPs in a murine breast cancer model," International Journal of Cancer, vol. 78, pp. 361-365, 1998.

[73] D. G. Duda, M. Sunamura, L. Lozonschi et al., "Direct in vitro evidence and in vivo analysis of the antiangiogenesis effects of interleukin 12," Cancer Research, vol. 60, pp. 1111-1116, 2000.

[74] C. Sgadari, A. L. Angiolillo, and G. Tosato, "Inhibition of angiogenesis by interleukin-12 is mediated by the interferon-inducible protein 10," Blood, vol. 87, pp. 38773882, 1996.

[75] E. E. Voest, B. M. Kenyon, M. S. O'Reilly, G. Truitt, R. J. D'Amato, and J. Folkman, "Inhibition of angiogenesis in vivo by interleukin 12," Journal of the National Cancer Institute, vol. 87, pp. 581-586, 1995.

[76] I. Airoldi, E. Di Carlo, B. Banelli et al., "The IL-12Rbeta2 gene functions as a tumor suppressor in human B cell malignancies," The Journal of Clinical Investigation, vol. 113, pp. 1651-1659, 2004.

[77] I. Airoldi, C. Cocco, E. Di Carlo et al., "Methylation of the IL$12 \mathrm{Rbeta} 2$ gene as novel tumor escape mechanism for pediatric B-acute lymphoblastic leukemia cells," Cancer Research, vol. 66, pp. 3978-3980, 2006.

[78] I. Airoldi, E. Di Carlo, C. Cocco et al., "Lack of Il12rb2 signaling predisposes to spontaneous autoimmunity and malignancy," Blood, vol. 106, pp. 3846-3853, 2005.

[79] B. T. Lin and L. M. Weiss, "Primary plasmacytoma of lymph nodes," Human Pathology, vol. 28, pp. 1083-1090, 1997.

[80] I. Airoldi, C. Cocco, N. Giuliani et al., "Constitutive expression of IL-12R beta 2 on human multiple myeloma cells delineates a novel therapeutic target," Blood, vol. 112, no. 3, pp. 750-759, 2008.

[81] X. Wang, X. Feng, J. Wang et al., "Bortezomib and IL-12 produce synergetic anti-multiple myeloma effects with reduced toxicity to natural killer cells," Anti-Cancer Drugs, vol. 25, no. 3, pp. 282-288, 2014.

[82] M. Q. Lacy, S. Jacobus, E. A. Blood, N. E. Kay, S. V. Rajkumar, and P. R. Greipp, "Phase II study of interleukin-12 for treatment of plateau phase multiple myeloma (E1A96): a trial of the Eastern Cooperative Oncology Group," Leukemia Research, vol. 33, no. 11, pp. 1485-1489, 2009.

[83] L. Hansson, A. O. Abdalla, A. Moshfegh et al., "Long-term idiotype vaccination combined with interleukin-12 (IL-12), or IL-12 and granulocyte macrophage colony-stimulating factor, in early-stage multiple myeloma patients," Clinical Cancer Research, vol. 13, no. 5, pp. 1503-1510, 2007.

[84] T. A. Fehniger and M. A. Caligiuri, "Interleukin 15: biology and relevance to human disease," Blood, vol. 97, pp. 14-32, 2001.

[85] T. A. Waldmann, "The biology of interleukin-2 and interleukin-15: implications for cancer therapy and vaccine design," Nature Reviews. Immunology, vol. 6, pp. 595-601, 2006.

[86] S. Sanjabi, M. M. Mosaheb, and R. A. Flavell, "Opposing effects of TGF-beta and IL-15 cytokines control the number of short-lived effector CD8+ T cells," Immunity, vol. 31, pp. 131-144, 2009.

[87] T. A. Stoklasek, K. S. Schluns, and L. Lefrancois, "Combined IL-15/IL-15Ralpha immunotherapy maximizes IL-15 activity in vivo," Journal of Immunology, vol. 177, pp. 6072-6080, 2006.

[88] S. Dubois, H. J. Patel, M. Zhang, T. A. Waldmann, and J. R. Muller, "Preassociation of IL-15 with IL-15R alphaIgG1-Fc enhances its activity on proliferation of $\mathrm{NK}$ and CD8+/CD44high T cells and its antitumor action," Journal of Immunology, vol. 180, pp. 2099-2106, 2008.

[89] M. Epardaud, K. G. Elpek, M. P. Rubinstein et al., "Interleukin-15/interleukin-15R alpha complexes promote destruction of established tumors by reviving tumor-resident CD8+ T cells," Cancer Research, vol. 68, pp. 2972-2983, 2008.

[90] C. Pappa, S. Miyakis, G. Tsirakis et al., "Serum levels of interleukin-15 and interleukin-10 and their correlation with proliferating cell nuclear antigen in multiple myeloma," Cytokine, vol. 37, pp. 171-175, 2007.

[91] W. Xu, M. Jones, B. Liu et al., "Efficacy and mechanism-ofaction of a novel superagonist interleukin-15: interleukin-15 receptor $\alpha \mathrm{Su} / \mathrm{Fc}$ fusion complex in syngeneic murine models of multiple myeloma," Cancer Research, vol. 73, no. 10, pp. 3075-3086, 2013.

[92] D. M. Center, H. Kornfeld, and W. W. Cruikshank, "Interleukin 16 and its function as a CD4 ligand," Immunology Today, vol. 17, pp. 476-481, 1996.

[93] V. M. Lauta, "A review of the cytokine network in multiple myeloma: diagnostic, prognostic, and therapeutic implications," Cancer, vol. 97, pp. 2440-2452, 2003.

[94] T. H. Rand, W. W. Cruikshank, D. M. Center, and P. F. Weller, "CD4-mediated stimulation of human eosinophils: lymphocyte chemoattractant factor and other CD4-binding ligands elicit eosinophil migration," The Journal of Experimental Medicine, vol. 173, pp. 1521-1528, 1991.

[95] M. G. Alexandrakis, F. H. Passam, D. S. Kyriakou et al., "Serum level of interleukin-16 in multiple myeloma patients and its relationship to disease activity," American Journal of Hematology, vol. 75, pp. 101-106, 2004.

[96] S. F. Long, G. A. Chen, and M. S. Fang, "Levels of interleukin-16 in peripheral blood of 52 patients with multiple myeloma and its clinical significance," International Journal of Clinical and Experimental Medicine, vol. 8, no. 12, pp. 22520-22524, 2015.

[97] D. Atanackovic, Y. Hildebrandt, J. Templin et al., "Role of interleukin 16 in multiple myeloma," Journal of the National Cancer Institute, vol. 104, no. 13, pp. 1005-1020, 2012.

[98] T. Kuwabara, F. Ishikawa, M. Kondo, and T. Kakiuchi, "The role of IL-17 and related cytokines in inflammatory 
autoimmune diseases," Mediators of Inflammation, vol. 2017, Article ID 3908061, 11 pages, 2017.

[99] C. Y. Du, R. Y. Yang, C. Li, and L. J. Duan, "Correlation of Th17 cells and IL-17 level in multiple myeloma patients with pathogenesis of multiple myeloma," Zhongguo Shi Yan Xue Ye Xue Za Zhi, vol. 25, no. 1, pp. 147-150, 2017.

[100] S. Campo, A. Allegra, A. D'Ascola et al., "MiRNome expression is deregulated in the peripheral lymphoid compartment of multiple myeloma," British Journal of Haematology, vol. 165, no. 6, pp. 801-813, 2014.

[101] Y. Li, B. Zhang, W. Li et al., "MiR-15a/16 regulates the growth of myeloma cells, angiogenesis and antitumor immunity by inhibiting Bcl-2, VEGF-A and IL-17 expression in multiple myeloma," Leukemia Research, vol. 49, pp. 73-79, 2016.

[102] J. A. Gracie, S. E. Robertson, and I. B. McInnes, "Interleukin18," Journal of Leukocyte Biology, vol. 73, pp. 213-224, 2003.

[103] K. Nakanishi, T. Yoshimoto, H. Tsutsui, and H. Okamura, "Interleukin-18 is a unique cytokine that stimulates both Th1 and Th2 responses depending on its cytokine milieu," Cytokine \& Growth Factor Reviews, vol. 12, pp. 53-72, 2001.

[104] Y. Li, N. Li, Z. Yan et al., "Dysregulation of the NLRP3 inflammasome complex and related cytokines in patients with multiple myeloma," Hematology, vol. 21, no. 3, pp. 144-151, 2016.

[105] M. G. Alexandrakis, F. H. Passam, K. Sfiridaki et al., "Interleukin-18 in multiple myeloma patients: serum levels in relation to response to treatment and survival," Leukemia Research, vol. 28, pp. 259-266, 2004.

[106] M. A. Amin, B. J. Rabquer, P. J. Mansfield et al., "Interleukin 18 induces angiogenesis in vitro and in vivo via Src and Jnk kinases," Annals of the Rheumatic Diseases, vol. 69, pp. 2204-2212, 2010.

[107] C. A. Pappa, M. G. Alexandrakis, A. Boula et al., "Emerging roles of endoglin/CD105 and angiogenic cytokines for disease development and progression in multiple myeloma patients," Hematological Oncology, vol. 31, no. 4, pp. 201-205, 2013.

[108] S. Trifari, C. D. Kaplan, E. H. Tran, N. K. Crellin, and H. Spits, "Identification of a human helper T cell population that has abundant production of interleukin 22 and is distinct from $\mathrm{T}(\mathrm{H})-17, \mathrm{~T}(\mathrm{H}) 1$ and $\mathrm{T}(\mathrm{H}) 2$ cells," Nature Immunology, vol. 10, pp. 864-871, 2009.

[109] M. Cella, A. Fuchs, W. Vermi et al., "A human natural killer cell subset provides an innate source of IL-22 for mucosal immunity," Nature, vol. 457, pp. 722-725, 2009.

[110] M. de Oliveira Neto, J. R. Ferreira Jr, D. Colau et al., "Interleukin-22 forms dimers that are recognized by two interleukin22R1 receptor chains," Biophysical Journal, vol. 94, pp. 1754-1765, 2008.

[111] L. Bleicher, P. R. de Moura, L. Watanabe et al., "Crystal structure of the IL-22/IL-22R1 complex and its implications for the IL-22 signaling mechanism," FEBS Letters, vol. 582, pp. 2985-2992, 2008.

[112] K. Boniface, F. X. Bernard, M. Garcia, A. L. Gurney, J. C. Lecron, and F. Morel, "IL-22 inhibits epidermal differentiation and induces proinflammatory gene expression and migration of human keratinocytes," Journal of Immunology, vol. 174, pp. 3695-3702, 2005.

[113] H. Ikeuchi, T. Kuroiwa, N. Hiramatsu et al., "Expression of interleukin-22 in rheumatoid arthritis: potential role as a proinflammatory cytokine," Arthritis and Rheumatism, vol. 52, pp. 1037-1046, 2005.
[114] K. Wolk, S. Kunz, E. Witte, M. Friedrich, K. Asadullah, and R. Sabat, "IL-22 increases the innate immunity of tissues," Immunity, vol. 21, pp. 241-254, 2004.

[115] H. Takatori, Y. Kanno, W. T. Watford et al., "Lymphoid tissue inducer-like cells are an innate source of IL-17 and IL-22," The Journal of Experimental Medicine, vol. 206, pp. 35-41, 2009.

[116] K. Wolk, E. Witte, K. Witte, K. Warszawska, and R. Sabat, "Biology of interleukin-22," Seminars in Immunopathology, vol. 32, p. 1731, 2010.

[117] S. Eyerich, K. Eyerich, D. Pennino et al., “Th22 cells represent a distinct human $\mathrm{T}$ cell subset involved in epidermal immunity and remodeling," The Journal of Clinical Investigation, vol. 119, pp. 3573-3585, 2009.

[118] K. E. Nograles, L. C. Zaba, A. Shemer et al., "IL-22-producing "T22" T cells account for upregulated IL-22 in atopic dermatitis despite reduced IL-17-producing TH17 T cells," The Journal of Allergy and Clinical Immunology, vol. 123, pp. 1244-1252.e2, 2009.

[119] Z. J. Ye, Q. Zhou, W. Yin et al., "Interleukin 22-producing CD4+ T cells in malignant pleural effusion," Cancer Letters, vol. 326, pp. 23-32, 2012.

[120] X. Xu, Y. Tang, S. Guo et al., "Increased intratumoral interleukin 22 levels and frequencies of interleukin 22-producing CD4+ T cells correlate with pancreatic cancer progression," Pancreas, vol. 43, pp. 470-477, 2014.

[121] I. Kryczek, Y. Lin, N. Nagarsheth et al., "IL-22(+)CD4(+) T cells promote colorectal cancer stemness via STAT3 transcription factor activation and induction of the methyltransferase DOT1L," Immunity, vol. 40, pp. 772-784, 2014.

[122] C. Musolino, A. Allegra, M. Ferraro et al., "Involvement of T2677T multidrug resistance gene polymorphism in interleukin 22 plasma concentration in B-chronic lymphocytic leukemia patients," Acta Oncologica, vol. 51, no. 3, pp. 406-408, 2012.

[123] S. Gangemi, A. Allegra, A. Alonci et al., "Interleukin 22 is increased and correlated with CD38 expression in patients with B-chronic lymphocytic leukemia," Blood Cells, Molecules \& Diseases, vol. 50, no. 1, pp. 39-40, 2013.

[124] G. Di Lullo, M. Marcatti, S. Heltai et al., "Th22 cells increase in poor prognosis multiple myeloma and promote tumor cell growth and survival," Oncoimmunology, vol. 4, no. 5, article e1005460, 2015.

[125] G. Tsirakis, C. A. Pappa, A. Kolovou, M. Kokonozaki, I. Neonakis, and M. G. Alexandrakis, "Clinical significance of interleukin-22 in multiple myeloma," Hematology, vol. 3, p. 143, 2015.

[126] E. Duvallet, L. Semerano, E. Assier, G. Falgarone, and M. C. Boissier, "Interleukin-23: a key cytokine in inflammatory diseases," Annals of Medicine, vol. 43, pp. 503-511, 2011.

[127] C. Parham, M. Chirica, J. Timans et al., "A receptor for the heterodimeric cytokine IL-23 is composed of IL-12Rbetal and a novel cytokine receptor subunit, IL-23R," Journal of Immunology, vol. 168, pp. 5699-5708, 2002.

[128] R. J. Carmody, Q. Ruan, H. C. Liou, and Y. H. Chen, "Essential roles of c-Rel in TLR-induced IL-23 p19 gene expression in dendritic cells," Journal of Immunology, vol. 178, pp. 186191, 2007.

[129] F. A. Verreck, T. de Boer, D. M. Langenberg et al., "Human IL-23-producing type 1 macrophages pro-mote but IL-10producing type 2 macrophages subvert immunity to 
(myco)bacteria," Proceedings of the National Academy of Sciences of the United States of America, vol. 101, pp. 4560-4565, 2004.

[130] J. L. Langowski, R. A. Kastelein, and M. Oft, "Swords into plowshares: IL-23 repurposes tumor immune surveillance," Trends in Immunology, vol. 28, pp. 207-212, 2007.

[131] J. L. Langowski, X. Zhang, L. Wu et al., "IL-23 promotes tumour incidence and growth," Nature, vol. 442, pp. 461465, 2006.

[132] E. Tartour, F. Fossiez, I. Joyeux et al., "Interleukin 17, a Tcell-derived cytokine, promotes tumorigenicity of human cervical tumors in nude mice," Cancer Research, vol. 59, pp. 3698-3704, 1999.

[133] S. Oniki, H. Nagai, T. Horikawa et al., "Interleukin-23 and interleukin-27 exert quite different antitumor and vaccine effects on poorly immunogenic melanoma," Cancer Research, vol. 66, pp. 6395-6404, 2006.

[134] S. Ugai, O. Shimozato, L. Yu et al., "Transduction of the IL-21 and IL-23 genes in human pancreatic carcinoma cells produces natural killer cell-dependent and -independent antitumor effects," Cancer Gene Therapy, vol. 10, pp. 771-778, 2003.

[135] X. Yuan, J. Hu, M. L. Belladonna, K. L. Black, and J. S. Yu, "Interleukin-23-expressing bone marrow-derived neural stem-like cells exhibit anti-tumor activity against intracranial glioma," Cancer Research, vol. 66, pp. 2630-2638, 2006.

[136] T. Kaiga, M. Sato, H. Kaneda, Y. Iwakura, T. Takayama, and H. Tahara, "Systemic administration of IL-23 induces potent antitumor immunity primarily mediated through Th1-type response in association with the endogenously expressed IL12," Journal of Immunology, vol. 178, pp. 7571-7580, 2007.

[137] W. W. Overwijk, K. E. de Visser, F. H. Tirion et al., "Immunological and antitumor effects of IL-23 as a cancer vaccine adjuvant," Journal of Immunology, vol. 176, pp. 5213-5222, 2006.

[138] M. G. Alexandrakis, C. A. Pappa, S. Miyakis et al., "Serum interleukin-17 and its relationship to angiogenic factors in multiple myeloma," European Journal of Internal Medicine, vol. 17, pp. 412-416, 2006.

[139] J. M. Quinn, N. A. Sims, H. Saleh et al., "IL-23 inhibits osteoclastogenesis indirectly through lymphocytes and is required for the maintenance of bone mass in mice," Journal of Immunology, vol. 181, pp. 5720-5729, 2008.

[140] S. Kamiya, C. Nakamura, T. Fukawa et al., "Effects of IL-23 and IL-27 on osteoblasts and osteoclasts: inhibitory effects on osteoclast differentiation," Journal of Bone and Mineral Metabolism, vol. 25, pp. 277-285, 2007.

[141] K. Noonan, L. Marchionni, J. Anderson, D. Pardoll, G. D. Roodman, and I. Borrello, "A novel role of IL-17-producing lymphocytes in mediating lytic bone disease in multiple myeloma," Blood, vol. 116, pp. 3554-3563, 2010.

[142] G. Trinchieri, S. Pflanz, and R. A. Kastelein, "The IL-12 family of heterodimeric cytokines: new players in the regulation of T cell responses," Immunity, vol. 19, pp. 641644, 2003.

[143] S. Pflanz, L. Hibbert, J. Mattson et al., "WSX-1 and glycoprotein 130 constitute a signal-transducing receptor for IL-27," Journal of Immunology, vol. 172, pp. 2225-2231, 2004.

[144] M. Xu, I. Mizoguchi, N. Morishima, Y. Chiba, J. Mizuguchi, and T. Yoshimoto, "Regulation of antitumor immune responses by the IL-12 family cytokines, IL-12, IL-23, and
IL-27," Clinical \& Developmental Immunology, vol. 2010, article 832454, 9 pages, 2010.

[145] C. Cocco, F. Morandi, and I. Airoldi, "Interleukin-27 and interleukin-23 modulate human plasmacell functions," Journal of Leukocyte Biology, vol. 89, pp. 729-734, 2011.

[146] F. Larousserie, P. Charlot, E. Bardel, J. Froger, R. A. Kastelein, and O. Devergne, "Differential effects of IL-27 on human B cell subsets," Journal of Immunology, vol. 176, pp. 58905897, 2006.

[147] M. Hisada, S. Kamiya, K. Fujita et al., "Potent antitumor activity of interleukin-27," Cancer Research, vol. 64, pp. 1152-1156, 2004.

[148] A. Vacca and D. Ribatti, "Bone marrow angiogenesis in multiple myeloma," Leukemia, vol. 20, pp. 193-199, 2006.

[149] N. Giuliani, S. Colla, M. Lazzaretti et al., "Proangiogenic properties of human myeloma cells: production of angiopoietin-1 and its potential relationship to myelomainduced angiogenesis," Blood, vol. 102, pp. 638-645, 2003.

[150] S. Uneda, F. Matsuno, T. Sonoki, I. Tniguchi, F. Kawano, and H. Hata, "Expressions of vascular endothelial growth factor and angiopoietin-2 in myeloma cells," Haematologica, vol. 88, pp. 113-115, 2003.

[151] L. Vincent, D. K. Jin, M. A. Karajannis et al., "Fetal stromaldependent paracrine and intracrine vascular endothelial growth factor-a/vascular endothelial growth factor receptor1 signaling promotes proliferation and motility of human primary myeloma cells," Cancer Research, vol. 65, pp. 31853192, 2005.

[152] J. R. Bradley, "TNF-mediated inflammatory disease," The Journal of Pathology, vol. 214, pp. 149-160, 2008.

[153] H. Wajant, K. Pfizenmaier, and P. Scheurich, "Tumor necrosis factor signaling," Cell Death and Differentiation, vol. 10, pp. 45-65, 2003.

[154] G. Olmos and J. Lladó, "Tumor necrosis factor alpha: a link between neuroinflammation and excitotoxicity," Mediators of Inflammation, vol. 2014, Article ID 861231, 12 pages, 2014.

[155] A. Hoffmann and D. Baltimore, "Circuitry of nuclear factor kappaB signaling," Immunological Reviews, vol. 210, pp. 171-186, 2006.

[156] Y. Dai, X. Y. Pei, M. Rahmani, D. H. Conrad, P. Dent, and S. Grant, "Interruption of the NF-kappaB pathway by Bay 11-7082 promotes UCN-01-mediated mitochondrial dysfunction and apoptosis in human multiple myeloma cells," Blood, vol. 103, pp. 2761-2770, 2004.

[157] J. J. Keats, R. Fonseca, M. Chesi et al., "Promiscuous mutations activate the noncanonical NF-kappaB pathway in multiple myeloma," Cancer Cell, vol. 12, pp. 131-144, 2007.

[158] P. Roy, T. Mukherjee, B. Chatterjee, B. Vijayaragavan, B. Banoth, and S. Basak, "Non-canonical NF $\kappa$ B mutations reinforce pro-survival TNF response in multiple myeloma through an autoregulatory RelB:p50 NF $\kappa \mathrm{B}$ pathway," Oncogene, pp. 1-13, 2016.

[159] K. Neben, J. Mytilineos, T. M. Moehler et al., "Polymorphisms of the tumor necrosis factor- $\alpha$ gene promoter predict for outcome after thalidomide therapy in relapsed and refractory multiple myeloma," Blood, vol. 100, pp. 2263-2265, 2002.

[160] K. Kadar, M. Kovacs, I. Karadi et al., "Polymorphism of TNFalpha and LT-alpha genes in multiple myeloma," Leukemia Research, vol. 32, pp. 1499-1504, 2008. 
[161] E. V. Iokupova, O. V. Grinchuk, D. K. Kalimullina et al., "Molecular genetic analysis of the IL-6 and tumor necrosis factor alpha gene polymorphisms in multiple myeloma," Molekuliarnaia Biologiia (Mosk), vol. 37, pp. 420-424, 2003.

[162] C. Basmacı, M. Pehlivan, A. G. Tomatır et al., "Effects of TNFalpha, NOS3, MDR1 gene polymorphisms on clinical parameters, prognosis and survival of multiple myeloma cases," Asian Pacific Journal of Cancer Prevention, vol. 17, no. 3, pp. 1009-1014, 2016.

[163] J. Du, Z. C. Yuan, C. Y. Zhang et al., "Effect of TNF-alpha gene polymorphism on outcome of thalidomide-based regimens for multiple myeloma," Zhonghau Xue Ye Xeu Za Zhi, vol. 30, pp. 649-653, 2009.

[164] L. E. Perez, N. Parque, K. Shain et al., "Bone marrow stroma confers resistance to Apo2 ligand/TRAIL in multiple myeloma in part by regulating c-FLIP," Journal of Immunology, vol. 180, pp. 1545-1555, 2008.

[165] H. Rauert, T. Stuhmer, R. Bargou, H. Wajant, and D. Siegmund, "TNFR1 and TNFR2 regulate the extrinsic apoptotic pathway in myeloma cells by multiple mechanisms," Cell Death \& Disease, vol. 2, article e194, 2011.

[166] Y. Kawano, M. Moschetta, S. Manier et al., "Targeting the bone marrow microenvironment in multiple myeloma," Immunological Reviews, vol. 263, pp. 160-172, 2015.

[167] V. Jurisic and M. Colovic, "Correlation of sera TNF-alpha with percentage of bone marrow plasma cells, LDH, beta2microglobulin, and clinical stage in multiple myeloma," Medical Oncology, vol. 19, pp. 133-139, 2002.

[168] M. Jourdan, K. Tarte, E. Legouffe, J. Brochier, J. F. Rossi, and B. Klein, "Tumor necrosis factor is a survival and proliferation factor for human myeloma cells," European Cytokine Network, vol. 10, pp. 65-70, 1999.

[169] X. S. Wang, Q. Shi, L. A. Williams et al., "Longitudinal analysis of patient-reported symptoms post-autologous stem cell transplant and their relationship to inflammation in patients with multiple myeloma," Leukemia \& Lymphoma, vol. 56, pp. 1335-1341, 2015.

[170] T. Latif, N. Chauhan, R. Khan, A. Moran, and S. Z. Usmani, "Thalidomide and its analogues in the treatment of multiple myeloma," Experimental Hematology \& Oncology, vol. 1, p. 27, 2012.

[171] C. Geng, J. Hou, Y. Zhao et al., "A multicenter, open-label phase II study of recombinant CPT (Circularly Permuted TRAIL) plus thalidomide in patients with relapsed and refractory multiple myeloma," American Journal of Hematology, vol. 89, pp. 1037-1042, 2014.

[172] G. W. Muller, R. Chen, S. Y. Huang et al., "Amino-substituted thalidomide analogs: potent inhibitors of TNF-alpha production," Bioorganic \& Medicinal Chemistry Letters, vol. 9, pp. 1625-1630, 1999.

[173] S. Marga, P. Gomez-Bougie, S. Bonnaud et al., "Paradoxical effect of lenalidomide on cytokine/growth factor profiles in multiple myeloma," British Journal of Cancer, vol. 108, pp. 1801-1806, 2013.

[174] A. Allegra, G. Penna, A. Alonci et al., "Monoclonal antibodies: potential new therapeutic treatment against multiple myeloma," European Journal of Haematology, vol. 90, no. 6, pp. 441-468, 2013.

[175] S. M. Collins, C. E. Bakan, G. D. Swartzel et al., "Elotuzumab directly enhances NK cell cytotoxicity against myeloma via CS1 ligation: evidence for augmented NK cell function complementing ADCC," Cancer Immunology, Immunotherapy, vol. 62, pp. 1841-1849, 2013.

[176] B. Balasa, R. Yun, N. A. Belmar et al., "Elotuzumab enhances natural killer cell activation and myeloma cell killing through interleukin-2 and TNF alpha pathways," Cancer Immunology, Immunotherapy, vol. 64, pp. 61-73, 2015.

[177] H. W. Lee, S. J. Park, B. K. Choi, H. H. Kim, K. O. Nam, and B. S. Kwon, "4-1BB promotes the survival of CD8+ T lymphocytes by increasing expression of Bcl-xL, and Bfl-1," Journal of Immunology, vol. 169, pp. 4882-4288, 2002.

[178] C. Chester, S. Ambulkar, and H. E. Kohrt, “4-1BB agonism: adding the accelerator to cancer immunotherapy," Cancer Immunology, Immunotherapy, vol. 65, pp. 1243-1248, 2016.

[179] A. Morales-Kastresana, E. Cataln, S. Hervas-Stubbs et al., "Essential complicity of perforin-granzyme and FAS-L mechanisms to achieve tumor rejection following treatment with anti-CD137 mAb," Journal for Immunotherapy of Cancer, vol. 1, p. 3, 2013.

[180] N. H. Segal, A. K. Gopal, S. Bhatia et al., "A phase 1 study of PF-0582566 (anti-4-1BB) in patients with advanced cancer," Journal of Clinical Oncology, vol. 32, supplement: abstract 3007, p. 5, 2014.

[181] J. Moreaux, E. Legouffe, E. Jourdan et al., "BAFF and APRIL protect myeloma cells from apoptosis induced interleukin 6 deprivation and dexamethasone," Blood, vol. 103, pp. 31483157, 2004.

[182] M. G. Alexandrakis, P. Roussou, C. A. Pappa et al., "Relationship between circulating BAFF serum levels with proliferating markers in patients with multiple myeloma," BioMed Research International, vol. 2013, Article ID 389579, 6 pages, 2013.

[183] M. Fragioudaki, A. Boula, G. Tsirakis et al., "B cell-activating factor: its clinical significance in multiple myeloma patients," Annals of Hematology, vol. 91, pp. 1413-1418, 2012.

[184] M. Fragioudaki, G. Tsirakis, C. A. Pappa et al., "Serum BAFF levels are related to angiogenesis and prognosis in patients with multiple myeloma," Leukemia Research, vol. 36, pp. 1004-1008, 2012.

[185] D. Lemancewicz, L. Bolkum, E. Jablonska et al., "Evaluation of TNF superfamily molecules in multiple myeloma patients: correlation with biological and clinical features," Leukemia Research, vol. 37, pp. 1089-1093, 2013.

[186] J. Hengeveld and J. Kersten, "B-cell activating factor in the pathophysiology of multiple myeloma: a target for therapy?," Blood Cancer Journal, vol. 27, p. 282, 2015.

[187] I. A. Abdelgawad, N. H. Radwan, R. E. Shafik, and H. A. Shokralla, "Significance of some proliferation markers and some prognostic factors in patients with multiple myeloma and their impact on the patients' survival," Asian Pacific Journal of Cancer Prevention, vol. 17, pp. 2389-2394, 2016.

[188] A. Billiau, H. Heremans, K. Vermeire, and P. Matthys, "Immunomodulatory properties of interferon-gamma. An update," Annals of the New York Academy of Sciences, vol. 856, pp. 22-32, 1998.

[189] A. E. Hauser, G. F. Debes, S. Arce et al., "Chemotactic responsiveness toward ligands for CXCR3 and CXCR4 is regulated on plasma blasts during the time course of a memory immune response," Journal of Immunology, vol. 169, pp. 1277-1282, 2002.

[190] C. Moller, T. Stromberg, M. Juremalm, K. Nilsson, and G. Nilsson, "Expression and function of chemokine receptors 
in human multiple myeloma," Leukemia, vol. 17, pp. 203210, 2003.

[191] K. Moser, G. Muehlinghaus, R. Manz et al., "Long-lived plasma cells in immunity and immunopathology," Immunology Letters, vol. 103, pp. 83-85, 2006.

[192] N. Giuliani, S. Bonomini, P. Romagnani et al., "CXCR3 and its binding chemokines in myeloma cells: expression of isoforms and potential relationships with myeloma cell proliferation and survival," Haematologica, vol. 91, pp. 1489-1497, 2006.

[193] L. Escoubet-Lozach, I. L. Lin, and K. Jensen-Pergakes, "Pomalidomide and lenalidomide induce p21 WAF-1 expression in both lymphoma and multiple myeloma through a LSD1-mediated epigenetic mechanism," Cancer Research, vol. 69, pp. 7347-7356, 2009.

[194] A. Lopez-Girona, D. Heintel, L. H. Zhang et al., "Lenalidomide downregulates the cell survival factor, interferon regulatory factor-4, providing a potential mechanistic link for predicting response," British Journal of Haematology, vol. 154, pp. 325-336, 2011.

[195] S. P. Eisenberg, R. J. Evans, W. P. Arend et al., "Primary structure and functional expression from complementary DNA of a human interleukin-1 receptor antagonist," Nature, vol. 343, pp. 341-346, 1990.

[196] S. Li, A. Strelow, E. J. Fontana, and H. Wesche, "IRAK-4: a novel member of the IRAK family with the properties of an IRAK-kinase," Proceedings of the National Academy of Sciences of the United States of America, vol. 99, pp. 5567-5572, 2002.

[197] G. Yang, Y. Zhou, X. Liu et al., "A mutation in MYD88 (L265P) supports the survival of lymphoplasmacytic cells by activation of bruton tyrosine kinase in Waldenstrom macroglobulinemia," Blood, vol. 122, pp. 1222-1232, 2013.

[198] A. Jain, S. Kaczanowska, and E. Davila, "IL-1 receptorassociated kinase signaling and its role in inflammation, cancer progression, and therapy resistance," Frontiers in Immunology, vol. 5, p. 553, 2014.

[199] A. Saxena, S. Khosraviani, S. Noel, D. Mohan, T. Donner, and A. R. Hamad, "Interleukin-10 paradox: a potent immunoregulatory cytokine that has been difficult to harness for immunotherapy," Cytokine, vol. 74, pp. 27-34, 2015.

[200] K. Josephson, N. J. Logsdon, and M. R. Walter, "Crystal structure of the IL-10/IL-10R1 complex reveals a shared receptor binding site," Immunity, vol. 15, pp. 35-46, 2001.

[201] D. Finbloom and K. Winestock, "IL-10 induces the tyrosine phosphorylation of tyk 2 and jak 1 and the differential assembly of STAT1 and STAT3 complexes in human T cells and monocytes," Journal of Immunology, vol. 155, pp. 10791090, 1995.

[202] M. Matsuda, F. Salazar, M. Petersson et al., "Interleukin 10 pretreatment protects target cells from tumor- and allospecific cytotoxic T cells and downregulates HLA class I expression," The Journal of Experimental Medicine, vol. 180, pp. 2371-2376, 1994.

[203] D. Miotto, N. Lo Cascio, M. Stendardo et al., "CD8+ T cells expressing IL-10 are associated with a favourable prognosis in lung cancer," Lung Cancer, vol. 69, pp. 355360, 2010.

[204] M. V. Lopez, S. K. Adris, A. I. Bravo, Y. Chernajovsky, and O. L. Podhajcer, "IL-12 and IL-10 expression synergize to induce the immune-mediated eradication of established colon and mammary tumors and lung metastasis," Journal of Immunology, vol. 175, pp. 5885-5894, 2005.

[205] S. Mocellin, F. M. Marincola, and H. A. Young, "Interleukin10 and the immune response against cancer: a counterpoint," Journal of Leukocyte Biology, vol. 78, pp. 1043-1051, 2005.

[206] D. Benjamin, C. D. Park, and V. Sharma, "Human B cell interleukin 10," Leukemia \& Lymphoma, vol. 12, pp. 205210, 1994.

[207] M. Gupta, J. Han, M. Stenson et al., "Elevated serum IL10 levels in diffuse large B cell lymphoma: a mechanism of aberrant JAK2 activation," Blood, vol. 119, pp. 2844-2853, 2012.

[208] E. Kovacs, "Interleukin-6 leads to interleukin-10 production in several human multiple myeloma cell lines. Does interleukin-10 enhance the proliferation of these cells?," Leukemia Research, vol. 34, pp. 912-916, 2010.

[209] C. Pappa, S. Miyakis, G. Tsirakis et al., "Serum levels of interleukin 15 and interleukin 10 and their correlation with proliferating cell nuclear antigen in multiple myeloma," Cytokine, vol. 37, pp. 171-5, 2007.

[210] H. Wang, L. Wang, P. Chi et al., "High level of interleukin-10 in serum predicts poor prognosis in multiple myeloma," British Journal of Cancer, vol. 114, no. 4, pp. 463-468, 2016.

[211] M. G. Alexandrakis, N. Goulidaki, C. A. Pappa et al., "Interleukin-10 induces both plasma cell proliferation and angiogenesis in multiple myeloma," Pathology Oncology Research, vol. 21, no. 4, pp. 929-934, 2015.

[212] T. Kasamatsu, T. Saitoh, R. Ino et al., "Polymorphism of IL10 receptor $\beta$ affects the prognosis of multiple myeloma patients treated with thalidomide and/or bortezomib," Hematological Oncology, pp. 1-8, 2016.

[213] Z. Y. Lu, X. G. Zhang, C. Rodriguez et al., "Interleukin-10 is a proliferation factor but not a differentiation factor for human myeloma cells," Blood, vol. 85, pp. 2521-2527, 1995.

[214] Z. J. Gu, V. Costes, Z. Y. Lu et al., "Interleukin-10 is a growth factor for human myeloma cells by induction of an oncostatin M autocrine loop," Blood, vol. 88, pp. 3972-3986, 1996.

[215] K. R. Muthu Raja, L. Kubiczkova, L. Rihova et al., "Functionally suppressive CD8 $\mathrm{T}$ regulatory cells are increased in patients with multiple myeloma: a cause for immune impairment," PLoS One, vol. 7, no. 11, article e49446, 2012.

[216] T. Otsuki, K. Yata, H. Sakaguchi et al., "Interleukin 10 abolishes the growth inhibitory effects of all-trans retinoic acid on human myeloma cells," British Journal of Haematology, vol. 116, no. 4, pp. 787-795, 2002.

[217] T. Kishimoto, S. Akira, M. Narazaki, and T. Taga, "Interleukin-6 family of cytokines and gp130," Blood, vol. 86, pp. 1243-1254, 1995.

[218] J. Bromberg, "Stat proteins and oncogenesis," The Journal of Clinical Investigation, vol. 109, pp. 1139-1142, 2002.

[219] C. Garbers, H. M. Hermanns, F. Schaper et al., "Plasticity and cross-talk of interleukin 6-type cytokines," Cytokine \& Growth Factor Reviews, vol. 23, pp. 85-97, 2012.

[220] H. Yu, D. Pardoll, and R. Jove, "STATs in cancer inflammation and immunity: a leading role for STAT3," Nature Reviews Cancer, vol. 9, pp. 798-809, 2009.

[221] U. Schwertschlag, W. Trepicchio, K. Dykstra, J. Keith, K. Turner, and A. Dorner, "Hematopoietic, immunomodulatory and epithelial effects of interleukin-11," Leukemia, vol. 13, pp. 1307-1315, 1999.

[222] M. Teramura, S. Kobayashi, K. Yoshinaga, K. Iwabe, and H. Mizoguchi, "Effect of interleukin 11 on normal and 
pathological thrombopoiesis," Cancer Chemotherapy and Pharmacology, vol. 38, pp. S99-S102, 1996.

[223] G. Huang, L. Yu, L. J. Cooper, M. Hollomon, H. Huls, and E. S. Kleinerman, "Genetically modified T cells targeting interleukin-11 receptor $\alpha$-chain kill human osteosarcoma cells and induce the regression of established osteosarcoma lung metastases," Cancer Research, vol. 72, pp. 271-281, 2012.

[224] H. Urbańska-Ryś, A. Wiersbowska, H. Stepień, and T. Robak, "Relationship between circulating interleukin-10 (IL-10) with interleukin-6 (IL-6) type cytokines (IL-6, interleukin-11 (IL11), oncostatin $M(\mathrm{OSM})$ ) and soluble interleukin-6 (IL-6) receptor (sIL-6R) in patients with multiple myeloma," European Cytokine Network, vol. 11, no. 3, pp. 443-451, 2000.

[225] N. Giuliani, S. Colla, F. Morandi, and V. Rizzoli, "The RANK/ RANK ligand system is involved in interleukin-6 and interleukin-11 up-regulation by human myeloma cells in the bone marrow microenvironment," Haematologica, vol. 89, no. 9, pp. 1118-1123, 2004.

[226] N. Giuliani, M. Ferretti, M. Bolzoni et al., "Increased osteocyte death in multiple myeloma patients: role in myelomainduced osteoclast formation," Leukemia, vol. 26, no. 6, pp. 1391-1401, 2012.

[227] C. B. Childs, J. A. Proper, R. F. Tucker, and H. L. Moses, "Serum contains a platelet-derived transforming growth factor," Proceedings of the National Academy of Sciences of the United States of America, vol. 79, pp. 5312-5316, 1982.

[228] J. L. Wrana, L. Attisano, R. Wieser, F. Ventura, and J. Massague, "Mechanism of activation of the TGF-beta receptor," Nature, vol. 370, pp. 341-347, 1994.

[229] A. Nakao, T. Imamura, S. Souchelnytskyi et al., “TGF-beta receptor-mediated signalling through $\mathrm{Smad} 2, \operatorname{Smad} 3$ and Smad4," The EMBO Journal, vol. 16, pp. 5353-5362, 1997.

[230] J. Massague and D. Wotton, "Transcriptional control by the TGF-beta/Smad signaling system," The EMBO Journal, vol. 19, pp. 1745-1754, 2000.

[231] L. Gorelik and R. A. Flavell, "Transforming growth factorbeta in T-cell biology," Nature Reviews. Immunology, vol. 2, pp. 46-53, 2002.

[232] J. J. Letterio and A. B. Roberts, "Regulation of immune responses by TGF-beta," Annual Review of Immunology, vol. 16, pp. 137-161, 1998.

[233] J. H. Kehrl, A. B. Roberts, L. M. Wakefield, S. Jakowiew, M. B. Sporn, and A. S. Fauci, "Transforming growth factor Beta is an important immunomodulatory protein for human B lymphocytes," Journal of Immunology, vol. 137, pp. 3855-3860, 1986.

[234] T. Hayashi, T. Hideshima, A. N. Nguyen et al., “Transforming growth factor beta receptor I kinase inhibitor downregulates cytokine secretion and multiple myeloma cell growth in the bone marrow microenvironment," Clinical Cancer Research, vol. 10, no. 22, pp. 7540-7546, 2004.

[235] K. E. Lambert, H. Huang, K. Mythreye, and G. C. Blobe, "The type III transforming growth factor- $\beta$ receptor inhibits proliferation, migration, and adhesion in human myeloma cells," Molecular Biology of the Cell, vol. 22, pp. 1463-1472, 2011.

[236] I. Bruns, R.P. cadeddu, I. Brueckmann et al., "TGF-b inhibition restores terminal osteoblast differentiation to suppress myeloma growth," PLoS One, vol. 5, article e9870, 2010.
[237] T. Matsumoto and M. Abe, "TGF- $\beta$-related mechanisms of bone destruction in multiple myeloma," Bone, vol. 48, pp. 129-134, 2011.

[238] M. A. Frassanito, K. DeVeirman, V. Desantis et al., "Halting pro-survival autophagy by TGF $\beta$ inhibition in bone marrow fibroblasts overcomes bortezomib resistance in multiple myeloma patients," Leukemia, vol. 30, no. 3, pp. 640-648, 2016.

[239] M. Dong and G. C. Blobe, "Role of transforming growth factor-beta in hematologic malignancies," Blood, vol. 107, pp. 4589-4596, 2006.

[240] N. O. Temajo and N. Howard, "The virus-induced HSPs regulate the apoptosis of operates APCs that results in autoimmunity, not in homeostasis," Autoimmunity Reviews, vol. 13, pp. 1013-1019, 2014.

[241] H. Udono, "Heat shock protein magic in antigen trafficking within dendritic cells: implications in antigen crosspresentation in immunity," Acta Medica Okayama, vol. 66, pp. 1-6, 2012.

[242] D. F. Terry, D. F. Wyszynski, V. G. Nolan et al., "Serum heat shock protein 70 level as a biomarker of exceptional longevity," Mechanisms of Ageing and Development, vol. 127, pp. 862-868, 2006.

[243] S. A. Fuqua, S. Oesterreich, S. G. Hilsenbeck, D. D. Von Hoff, J. Eckardt, and C. K. Osborne, "Heat shock proteins and drug resistance," Breast Cancer Research and Treatment, vol. 32, pp. 67-71, 1994.

[244] L. M. Vargas-Roig, F. E. Gago, O. Tello, J. C. Aznar, and D. R. Ciocca, "Heat shock protein expression and drug resistance in breast cancer patients treated with induction chemotherapy," International Journal of Cancer, vol. 79, pp. $468-475,1998$.

[245] J. S. Isaacs, W. Xu, and L. Neckers, "Heat shock protein 90 as a molecular target for cancer therapeutics," Cancer Cell, vol. 3, pp. 213-217, 2003.

[246] A. Mahindra, D. Cirstea, and N. Raje, "Novel therapeutic targets for multiple myeloma," Future Oncology, vol. 6, pp. 407-418, 2010.

[247] S. Takayama, J. C. Reed, and S. Homma, "Heat-shock proteins as regulators of apoptosis," Oncogene, vol. 22, pp. 9041-9047, 2003.

[248] L. Whitesell and S. L. Lindquist, "HSP90 and the chaperoning of cancer," Nature Reviews. Cancer, vol. 5, pp. 761-772, 2005.

[249] T. Van den Berghe, M. Kalai, G. van Loo, W. Declercq, and P. Vandenabeele, "Disruption of HSP90 function reverts tumor necrosis factor-induced necrosis to apoptosis," The Journal of Biological Chemistry, vol. 278, pp. 5622-5629, 2003.

[250] G. Chen, P. Cao, and D. V. Goeddel, “TNF-induced recruitment and activation of the IkK complex require Cdc37 and HSP90," Molecular Cell, vol. 9, pp. 401-410, 2002.

[251] F. M. Falsone, S. Leptihn, A. Osterauer, M. Haslbeck, and J. Buchner, "Oncogenic mutations reduce the stability of Src kinase," Journal of Molecular Biology, vol. 344, pp. 281-291, 2004.

[252] L. Whitesell, P. D. Sutphin, E. J. Pulcini, J. D. Martinez, and P. H. Cook, "The physical association of multiple molecular chaperone proteins with mutant $\mathrm{p} 53$ is altered by geldanamycin, an HSP90-binding agent," Molecular and Cellular Biology, vol. 18, pp. 1517-1524, 1998.

[253] L. Whitesell, E. G. Mimnaugh, B. De Costa, C. E. Myers, and L. M. Neckers, "Inhibition of heat shock protein HSP90- 
pp60v-src heteroprotein complex formation by benzoquinone ansamycins: essential role for stress proteins in oncogenic transformation," Proceedings of the National Academy of Sciences of the United States of America, vol. 91, pp. 8324-8328, 1994.

[254] A. Stephanou, D. A. Isenberg, S. Akira, T. Kishimoto, and D. S. Latchman, "The nuclear factor interleukin-6 (NF-IL6) and signal transducer and activator of transcription-3 (STAT-3) signalling pathways co-operate to mediate the activation of the HSP90beta gene by interleukin- 6 but have opposite effects on its inducibility by heat shock," The Biochemical Journal, vol. 330, pp. 1189-1195, 1998.

[255] D. V. Kalvakolanu and S. K. Roy, "CCAAT/enhancer binding proteins and interferon signaling pathways," Journal of Interferon \& Cytokine Research, vol. 25, pp. 757-769, 2005.

[256] M. Andrulis, M. Chatterjee, S. Jain et al., "Heat shock protein 90 alpha and beta are overexpressed in multiple myeloma cells and critically contribute to survival," Verhandlungen der Deutschen Gesellschaft für Pathologie, vol. 91, pp. 330337, 2009.

[257] A. Allegra, E. Sant'Antonio, G. Penna et al., "Novel therapeutic strategies in multiple myeloma: role of the heat shock protein inhibitors," European Journal of Haematology, vol. 86, no. 2, pp. 93-110, 2011.

[258] N. Mitsiades, C. S. Mitsiades, P. G. Richardson et al., "Molecular sequelae of histone deacetylase inhibition in human malignant B cells," Blood, vol. 101, pp. 4055-4062, 2003.

[259] X. Y. Pei, Y. Dai, and S. Grant, "Synergistic induction of oxidative injury and apoptosis in human multiple myeloma cells by the proteasome inhibitor bortezomib and histone deacetylase inhibitors," Clinical Cancer Research, vol. 10, pp. 3839-3852, 2004.

[260] C. Y. Gui, L. Ngo, W. S. Xu, V. M. Richon, and P. A. Marks, "Histone deacetylase (HDAC) inhibitor activation of p21WAF1 involves changes in promoter-associated proteins, including HDAC1," Proceedings of the National Academy of Sciences of the United States of America, vol. 101, pp. 12411246, 2004.

[261] Y. Imai, Y. Maru, and J. Tanaka, “Action mechanisms of histone deacetylase inhibitors in the treatment of hematological malignancies," Cancer Science, vol. 107, pp. 1543-1549, 2016.

[262] Y. Xie, O. Bai, H. Zhang et al., "Membrane-bound HSP70engineered myeloma cell-derived exosomes stimulate more efficient CD8+ CTL- and NK-mediated antitumour immunity than exosomes released from heat-shocked tumour cells expressing cytoplasmic HSP70," Journal of Cellular and Molecular Medicine, vol. 11, pp. 2655-2666, 2010.

[263] S. H. Jung, Y. K. Lee, H. J. Lee et al., "Dendritic cells loaded with myeloma cells pretreated with a combination of JSI124 and bortezomib generate potent myeloma-specific cytotoxic T lymphocytes in vitro," Experimental Hematology, vol. 42, pp. 274-281, 2014.

[264] S. C. Larsson and A. Wolk, "Body mass index and risk of multiple myeloma: a meta-analysis," International Journal of Cancer, vol. 121, pp. 2512-2516, 2007.

[265] M. Dalamaga, "Interplay of adipokines and myokines in cancer pathophysiology: emerging therapeutic implications," World Journal of Experimental Medicine, vol. 3, no. 3, pp. 26-33, 2013.

[266] I. Mahú and A. I. Domingos, "The sympathetic neuroadipose connection and the control of body weight," Experimental Cell Research, 2017.
[267] A. Pérez-Pérez, T. Vilariño-García, P. Fernández-Riejos, J. Martín-González, J. J. Segura-Egea, and V. Sánchez-Margalet, "Role of leptin as a link between metabolism and the immune system," Cytokine \& Growth Factor Reviews, vol. 35, pp. 71-84, 2017.

[268] F. Corica, A. Allegra, A. Corsonello et al., "Relationship between plasma leptin levels and the tumor necrosis factor-alpha system in obese subjects," International Journal of Obesity and Related Metabolic Disorders, vol. 23, no. 4, pp. 355-360, 1999.

[269] J. N. Hofmann, L. M. Liao, M. N. Pollak et al., "A prospective study of circulating adipokine levels and risk of multiple myeloma," Blood, vol. 120, no. 22, pp. 4418-4420, 2012.

[270] N. E. Esheba, A. Shahba, and O. El Shora, "Assessment of leptin and resistin levels in non-obese multiple myeloma patients and their relation with Ig level and disease stage," Journal of the Egyptian National Cancer Institute, vol. 26, pp. 61-66, 2014.

[271] M. G. Alexandrakis, F. H. Passam, A. Sfiridaki et al., "Serum levels of leptin in multiple myeloma patients and its relation to angiogenic and inflammatory cytokines," The International Journal of Biological Markers, vol. 19, pp. 52-57, 2004.

[272] I. Ray, S. K. Mahata, and R. K. De, "Obesity: an immunometabolic perspective," Frontiers in Endocrinology, vol. 7, p. 157, 2016.

[273] R. V. Considine, M. K. Sinha, M. L. Heiman et al., "Serum immunoreactive-leptin concentrations in normal-weight and obese humans," The New England Journal of Medicine, vol. 334, pp. 292-295, 1996

[274] P. Rider, Y. Carmi, and I. Cohen, "Biologics for targeting inflammatory cytokines, clinical uses, and limitations," International Journal of Cell Biology, vol. 2016, Article ID 9259646, 11 pages, 2016.

[275] H. Quach, D. Ritchie, A. K. Stewart et al., "Mechanism of action of immunomodulatory drugs (IMiDS) in multiple myeloma," Leukemia, vol. 24, no. 1, pp. 22-32, 2010.

[276] V. Kotla, S. Goel, S. Nischal et al., "Mechanism of action of lenalidomide in hematological malignancies," Journal of Hematology \& Oncology, vol. 2, p. 36, 2009.

[277] L. G. Corral, P. A. Haslett, G. W. Muller et al., "Differential cytokine modulation and $\mathrm{T}$ cell activation by two distinct classes of thalidomide analogues that are potent inhibitors of TNF-alpha," Journal of Immunology, vol. 163, no. 1, pp. 380-386, 1999.

[278] T. Harada, S. Ozaki, A. Oda et al., "Association of Th1 and Th2 cytokines with transient inflammatory reaction during lenalidomide plus dexamethasone therapy in multiple myeloma," International Journal of Hematology, vol. 97, pp. 743-748, 2013.

[279] S. Zha, V. Yegnasubramanian, W. G. Nelson, W. B. Isaacs, and A. M. De Marzo, "Cyclooxygenases in cancer: progress and perspective," Cancer Letters, vol. 215, pp. 1-20, 2004.

[280] M. Ladetto, S. Vallet, A. Trojan et al., "Cyclooxygenase-2 (COX-2) is frequently expressed in multiple myeloma and is an independent predictor of poor outcome," Blood, vol. 105, pp. 4784-4791, 2005.

[281] A. Trojan, M. Tinguely, S. Vallet et al., "Clinical significance of cyclooxygenase-2 (COX-2) in multiple myeloma," Swiss Medical Weekly, vol. 136, pp. 400-403, 2006.

[282] M. Cetin, S. Buyukberber, M. Demir et al., "Overexpression of cyclooxygenase-2 in multiple myeloma: association with 
reduced survival," American Journal of Hematology, vol. 80, pp. 169-173, 2005.

[283] M. Zhang, Y. Abe, T. Matsushima, J. Nishimura, H. Nawata, and K. Muta, "Selective cyclooxygenase 2 inhibitor NS-398 induces apoptosis in myeloma cells via a Bcl-2 independent pathway," Leukemia \& Lymphoma, vol. 46, pp. 425-433, 2005.

[284] J. Ding, K. Tsuboi, H. Hoshikawa et al., "Cyclooxygenase isozymes are expressed in human myeloma cells but not involved in anti-proliferative effect of cyclooxygenase inhibitors," Molecular Carcinogenesis, vol. 45, pp. 250259, 2006.

[285] R. Khan, M. Sharma, L. Kumar, S. Akhtar Husain, and A. Sharma, "Interrelationship and expression profiling of cyclooxygenase and angiogenic factors in Indian patients with multiple myeloma," Annals of Hematology, vol. 92, pp. 101-109, 2013.

[286] P. L. Minciullo, A. Catalano, G. Mandraffino et al., "Inflammaging and anti-inflammaging: the role of cytokines in extreme longevity," Archivum Immunologiae et Therapiae Experimentalis, vol. 64, no. 2, pp. 111-126, 2015.

[287] D. Monti, R. Ostan, V. Borell, G. Castellani, and C. Franceschi, "Inflammaging and human longevity in the omics era," Mechanisms of Ageing and Development, vol. 165, Part B, pp. 129-138, 2016.

[288] K. Klintrup, J. M. Mäkinen, S. Kauppila et al., "Inflammation and prognosis in colorectal cancer," European Journal of Cancer, vol. 41, no. 17, pp. 2645-2654, 2005.

[289] A. H. Lee, C. E. Gillett, K. Ryder, I. S. Fentiman, D. W. Miles, and R. R. Millis, "Different patterns of inflammation and prognosis in invasive carcinoma of the breast," Histopathology, vol. 48, no. 6, pp. 692-701, 2006.

[290] T. Cai, G. Nesi, V. Boddi, S. Mazzoli, M. Dal Canto, and R. Bartoletti, "Prognostic role of the tumor-associated tissue inflammatory reaction in transitional bladder cell carcinoma," Oncology Reports, vol. 16, no. 2, pp. 329-334, 2006.

[291] S. Z. Ben-Sasson, J. Hu-Li, J. Quiel et al., "IL-1 acts directly on CD4 $\mathrm{T}$ cells to enhance their antigen-driven expansion and differentiation," Proceedings of the National Academy of Sciences of the United States of America, vol. 106, no. 17, pp. 7119-7124, 2009.

[292] O. A. W. Haabeth, K. B. Lorvik, C. Hammarström et al., "Inflammation driven by tumour-specific Th1 cells protects against B-cell cancer," Nature Communications, vol. 2, p. 240, 2011.

[293] L. Zhang, J. R. Conejo-Garcia, D. Katsaros et al., "Intratumoral T cells, recurrence, and survival in epithelial ovarian cancer," The New England Journal of Medicine, vol. 348, no. 3, pp. 203-213, 2003.

[294] J. Galon, A. Costes, F. Sanchez-Cabo et al., "Type, density, and location of immune cells within human colorectal tumors predict clinical outcome," Science, vol. 313, no. 5795, pp. 1960-1964, 2006.

[295] W. W. Lin and M. Karin, "A cytokine-mediated link between innate immunity, inflammation, and cancer," The Journal of Clinical Investigation, vol. 117, pp. 1175-1183, 2007.

[296] A. Mantovani, P. Allavena, A. Sica, and F. Balkwill, "Cancerrelated inflammation,” Nature, vol. 454, pp. 436-444, 2008.

[297] S. Kim, H. Takahashi, W. W. Lin et al., "Carcinoma-produced factors activate myeloid cells through TLR2 to stimulate metastasis," Nature, vol. 457, no. 7225, pp. 102-106, 2009.
[298] E. J. Park, J. H. Lee, G. Y. Yu et al., "Dietary and genetic obesity promote liver inflammation and tumorigenesis by enhancing IL-6 and TNF expression," Cell, vol. 140, no. 2, pp. 197-208, 2010.

[299] R. Philip and L. B. Epstein, "Tumour necrosis factor as immunomodulator and mediator of monocyte cytotoxicity induced by itself, gamma-interferon and interleukin-1," Nature, vol. 323, pp. 86-89, 1986.

[300] F. Martinon, A. Mayor, and J. Tschopp, "The inflammasomes: guardians of the body," Annual Review of Immunology, vol. 27, pp. 229-265, 2009.

[301] F. Ghiringhelli, L. Apetoh, A. Tesniere et al., "Activation of the NLRP3 inflammasome in dendritic cells induces IL1beta-dependent adaptive immunity against tumors," Nature Medicine, vol. 15, no. 10, pp. 1170-1178, 2009.

[302] A. Allegra, G. Penna, A. Alonci, V. Rizzo, S. Russo, and C. Musolino, "Nanoparticles in oncology: the new theragnostic molecules," Anti-Cancer Agents in Medicinal Chemistry, vol. 11, no. 7, pp. 669-686, 2011.

[303] M. J. Mitchell, J. Webster, A. Chung, P. P. Guimarães, O. F. Khan, and R. Langer, "Polymeric mechanical amplifiers of immune cytokine-mediated apoptosis," Nature Communications, vol. 8, article 14179, 2017.

[304] V. Shukla, M. Dalela, M. Vij et al., "Systemic delivery of the tumor necrosis factor gene to tumors by a novel dual DNA-nanocomplex in a nanoparticle system," Nanomedicine, vol. 13, no. 5, pp. 1833-1839, 2017. 


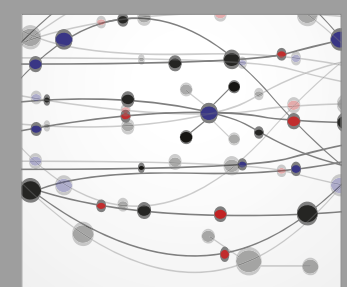

The Scientific World Journal
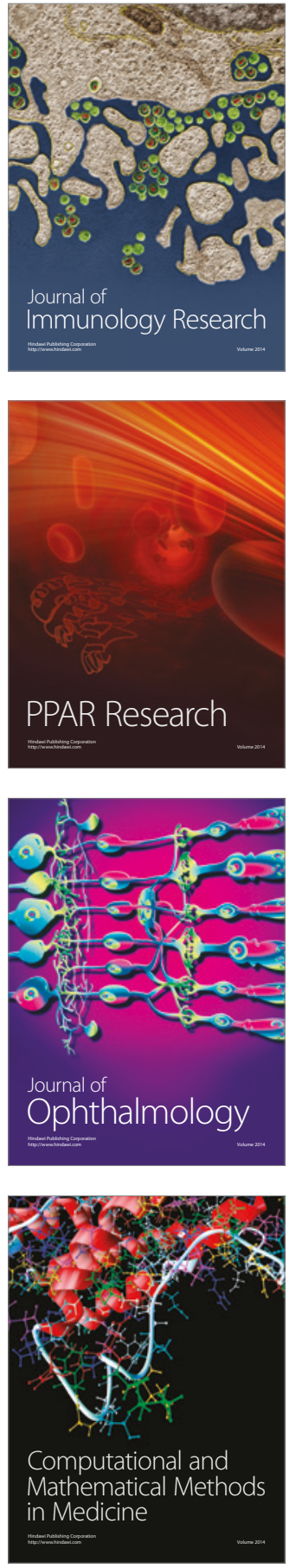

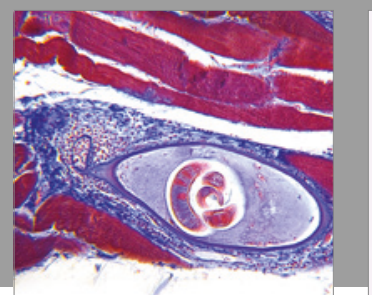

Gastroenterology Research and Practice
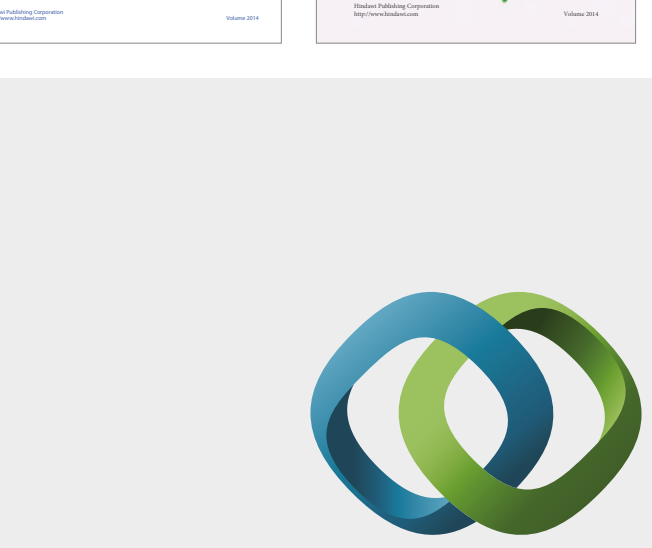

\section{Hindawi}

Submit your manuscripts at

https://www.hindawi.com
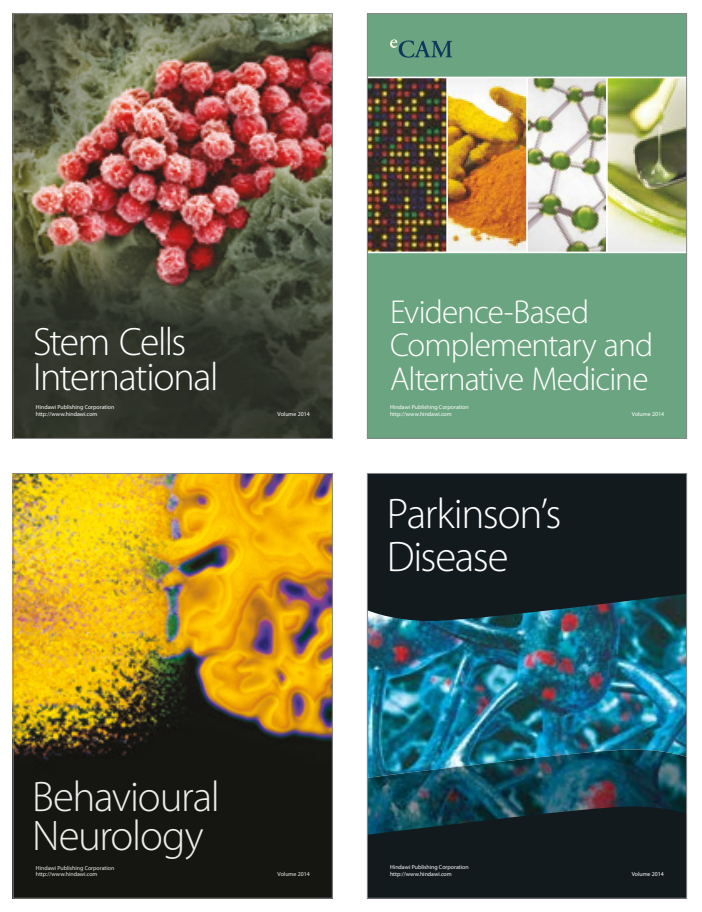
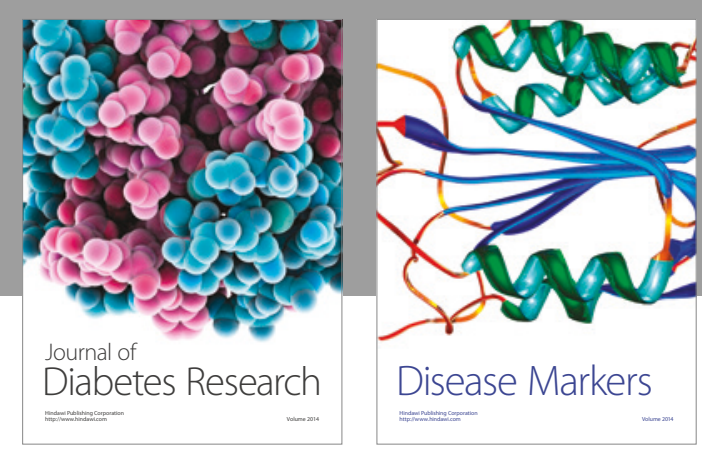

Disease Markers
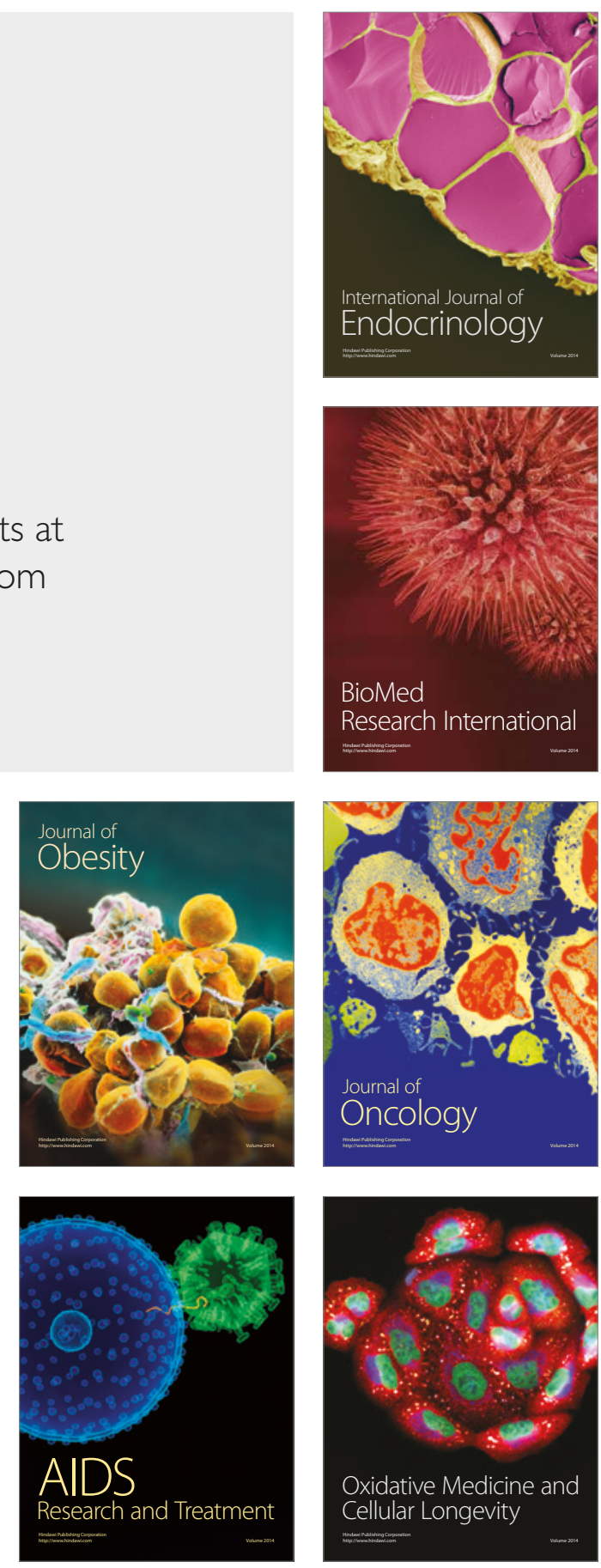